\title{
Moralizing the Production and Sale of Student Papers in Uganda
}

\author{
Margaret Frye* and Anna Woźny** \\ Forthcoming, American Sociological Review
}

\begin{abstract}
Sociologists have shown that moral understandings of market exchanges can differ between historical periods and institutional settings, but have paid less attention to how producers' moral frameworks vary depending on their unequal positions within both markets and institutions. We use interviews and ethnographic observations to examine the vibrant market of research shops selling academic work to students around two of Uganda's top universities. We identify three groups of researchers - Knowledge Producers, Entrepreneurs, and Educatorswho construct different professional identities and moral justifications of their trade, and orient their market action accordingly. We demonstrate that these identities and moral frameworks reflect an interplay between the institutional contexts and the social class positions that researchers occupy within this illicit market. While Knowledge Producers and Entrepreneurs both experienced a sense of "fit" with their respective institutional cultures, the former now see their work as compromising ideals of research, whereas the latter capitalize on what they view as a broken system. Educators, disadvantaged at both institutions, articulate a framework countering the dominant institutional cultures and sympathetic to underperforming students. This approach illuminates how institutional contexts and individual class positions within them influence producers' moral frameworks, leading to differentiation of the market.
\end{abstract}

* Corresponding Author. Assistant Professor, Department of Sociology, University of Michigan. Address: 3148 LSA Building 500 S. State Street, Ann Arbor MI 48109, email: mtfrye@umich.edu, phone: (510) 207-5006.

** Ph.D. Candidate, Department of Sociology, University of Michigan

Keywords: morality, illicit markets, inequality, institutional cultures, higher education, sub-Saharan Africa

Acknowledgements: We are grateful for comments and feedback on earlier drafts of this article to Pablo Gastón, Erin Cech, Elizabeth Armstrong, Roi Livne, Elizabeth Popp Berman, and Luis Flores as well as the participants in the University of North Carolina Culture and Politics workshop and the University of Michigan Economic Sociology and Organizations workshop. We are also grateful to Davis Ainebyona, Deborah Birungi, and Boreen Tumuhairwe for their research assistance.

Funding: Financial support was provided by a Fulbright Scholar grant and by Research reported in this publication was supported by a Fulbright Scholar grant and by National Institute of Child Health and Human Development Center Grant P2CHD041028. 
The purchasing of assignments from an online industry of "essay mills" has grown rampant within universities around the world (Stockman and Mureithi 2019; Smith 2019), with more than 15 percent of students worldwide estimated to be outsourcing their work (Newton 2018). In many cases, purchased essays are written by university-educated young adults in developing countries, whose access to formal employment has been compromised (Stockman and Mureithi 2019). This expanding global market for student research reveals that the production of academic work is enmeshed in market forces and individual pecuniary interests. Within this global market, the size and character of the moral panic sparked by students' outsourcing of academic work, as well as definitions of academic misconduct, vary across cultures and contexts (Decoo 2001; Newton 2018), suggesting that boundaries between legitimate and illegitimate academic work are themselves culturally mediated.

This article investigates a case where an open and vibrant market has emerged for buying and selling academic papers. Whereas the global circulation of essays typically occurs through anonymous and virtual one-time transactions, in Kampala, Uganda, the purchasing of academic work involves in-person social relationships that unfold over several months. Professional researchers ${ }^{1}$ working in "research shops" located around university campuses are hired by student-clients to write their final-year research reports, coach them on how to defend the work to their faculty supervisors, and make revisions based on supervisors' feedback. This practice is pervasive; several students and faculty we spoke with stated that a majority of Ugandan students engage in this trade (see also Kaija 2017). It is also illicit - it violates university policies and can lead to sanctions. As we show, the researchers who sell this work to students develop varied professional identities and moral understandings of their participation in this trade, which reflect an interplay between institutional contexts and the class-stratified positions that researchers occupy within them.

This research contributes to a body of work within sociology that examines the moralization of economic actions: the ideals, norms, and narratives that people mobilize when justifying and legitimizing their market activity (e.g., Fourcade 2011; Healy 2006; Zelizer 1983; 2005). This literature has often privileged a diachronic perspective, showing how various understandings of a given commodity change over time (Fourcade 2011; Livne 2014; Quinn 2008; Zelizer 1983), while paying less attention to why individuals might simultaneously hold different moral views. Other approaches have demonstrated that various moral frameworks are institutionally anchored (Anteby 2010; Reich 2014); however, they have typically assumed that market actors nearly uniformly subscribe to shared cultural norms that are dominant in a given institutional context. In contrast, we demonstrate that the distinct moral frameworks embraced by market actors emerge as a result of their unequal positioning within particular institutional contexts.

This "moralized markets" perspective has focused predominantly on discrete economic transactions as sites of moral meaning (Fourcade 2012; Zelizer 1997;2005), but has paid less attention to the producers of the commodities being traded (see Anteby 2010 for an exception). Drawing upon research that examines workers' differing moral orientations in various markets,

\footnotetext{
${ }^{1}$ Throughout the manuscript, we refer to producers in the student research market as researchers; this term is routinely used in Kampala by students, faculty, and the researchers themselves. To describe the faculty members who advise and evaluate the research, we adopt the locally-used term supervisors. Because of the dual role that students occupy in these transactions, we use the term student-client, though researchers often use "client" and "student."
} 
including in the field of knowledge production (Daston 1995; Lucier 2009; Shapin 1994; 2008), we show that the market for student research is differentiated by groups of producers, whose classstratified university experiences continue to shape their professional identities and their understandings of the student research market. These class-based distinctions among groups of producers are an important source of variation in both the moral meanings as well as the products and services that circulate within a market.

The researchers in this study espoused three distinct moral frameworks encompassing contrasting understandings of academic misconduct, attributions of culpability for the emergence of the illicit market, and definitions of good and bad work. We call these groups Knowledge Producers, Entrepreneurs, and Educators. Most Knowledge Producers attended and now work near Flagship, Uganda's premier university. ${ }^{2}$ They experienced a sense of "fit" with an elite university culture valorizing research and academic excellence. Knowledge Producers' moral understanding of their work mirrors this institutional culture; they disparage lazy students and less scrupulous researchers for creating fabricated reports, while emphasizing their own analytic skills and passionate pursuit of true knowledge. Most Entrepreneurs attended Technical, a mid-tier public university focused on engineering and business studies, and now work in the bustling student research market nearby. Entrepreneurs experienced a sense of "fit" with the institutional culture at Technical, which valorizes financial success, industriousness, and entrepreneurship over knowledge production and academic merit. Their moral understandings reflect this institutional culture: they argue that everyone is complicit in the inevitable market for student research, and emphasize their ability to satisfy clients and expand their businesses. Educators attended both Flagship and Technical. Their experience as students was marred by financial precarity, academic struggle, and social isolation. They accordingly construct moral understandings in opposition to the dominant cultures of both campuses - they justify their participation in the research market by emphasizing their ability to equip students with necessary skills that their classes fail to teach.

These systematic differences underscore the key roles played by identity work (Snow and Anderson 1987) and justification practices (Boltanski and Thevenot 2006) in linking people's positions in a social hierarchy with their moralization of contested market activity. Researchers' unequal social positionings within hierarchically-organized institutional contexts influence the identity projects they pursue and the moral distinctions they draw between themselves and other market actors. These identities and distinctions, in turn, shape how they justify their own participation in the market and morally evaluate other market actors. Taken together, these cultural processes lead to distinct practices of production. Our findings have implications for scholarship on the intersection of morality and economic action, for sociologists interested in how cultural meanings are shaped by social inequality at the micro level, and for scholars interested in emergent forms of knowledge production.

\footnotetext{
${ }^{2}$ We use pseudonyms for the two universities, to respect the institutions' digital privacy and to avoid triggering punitive actions towards the researchers themselves. We do not intend to mask the locations entirely; readers who are knowledgeable about higher education in Uganda will easily be able to identify them. Details about these two institutional contexts are important for understanding both our empirical case and our theoretical argument, and have therefore not been altered.
} 


\section{THEORETICAL FRAMEWORK}

\section{The Place for Producers in Moralized Markets}

In examining the moral frameworks surrounding market actors' participation in a market, we build on a rich tradition within economic sociology of viewing economic transactions themselves as morality-laden (Anteby 2010; Fourcade and Healy 2007; Livne 2014; Quinn 2008; Zelizer 1983). Economic activity, according to this perspective, is both "moralized and moralizing" (Fourcade and Healy 2007, p. 286); the market transforms norms and ideals, and those very norms and ideals in turn influence market transactions (Bandelij 2020; Wherry 2012). This moralized markets approach has shown, for instance, that market participants mobilize culturally salient moral justifications in order to render seemingly untradeable goods - including life, death, knowledge, body parts, and natureexchangeable in markets (see Anteby 2010; Fourcade 2011; Healy 2006; Quinn 2008; Zelizer 1983). However, despite a rich trove of data and theorizing about the moral implications of market activity, this literature has thus far been less attentive to the unequal social positioning of market participants. We identify two aspects of this perspective that we believe have led to an underappreciation of the role of social inequality in shaping moral understandings.

First, the moralized markets approach has largely assumed that participants occupying a similar role in the same market context develop a shared set of meanings about a given commodity. Some scholars emphasize temporal variation, demonstrating how new moral justifications come to be institutionalized and taken for granted as "legitimizing narratives" (Livne 2014), adopted by the broader society. For instance, during the nineteenth century, the purchase of life insurance evolved from a source of shame to a moral obligation when the industry successfully linked purchasing insurance to the quandary of how to provide for relatives while facing death (Zelizer 1983). This approach usefully captures depictions of a dominant ethos of an era, but does not attend as closely to heterogeneity in moral views held contemporaneously by actors within the same market.

More recently, scholars of morals and markets have attended to differences in moral sensemaking across institutional settings (Altomonte 2020; Anteby 2010; Reich 2014). This work demonstrates that institutional narratives imbue economic activity with moral meanings in ways that extend beyond the evaluations of individual people (Quinn 2008; Reich 2014). Nevertheless, this work has implicitly assumed that actors occupy similar social positions as they move together through institutions and thus develop similar moral frameworks (e.g., Anteby 2010; Healy 2006; Quinn 2008; Reich 2014; though see Altomonte 2020 for a recent exception).

A parallel strain of scholarship within the moralized markets literature, focused not on the moral meanings of commodities but rather on those surrounding purchases, attends more centrally to differences across market participants. This literature examines how people develop and maintain different boundaries and moral standards for how purchases should unfold, depending on their social position and on their relationship to others (Bandelj 2020; Wherry 2012; Zelizer 1997). These distinctions are articulated in several ways. Different currencies (standard money, bartered goods, government-issued coupons) are used to mark different social relations (Zelizer 1997; Dodd 2005; Wherry 2012). Purchases are paid from different sources (husbands' work, wives' side businesses, tax refunds) - and these different pots of money are culturally coded, for example, as "clean" versus "dirty" or "necessary" versus "luxury" (Bandelj 2020; Carruthers and Espeland 1998; Zelizer 2005). Such practices, scholars note, can lead to segmentation within markets - creating different circuits of 
economic activity within them (Zelizer 1997), which vary across ethnicity, gender, or other axes of differentiation among consumers.

This brings us, however, to our second critique: the moralized markets literature has, as a whole, focused largely on discrete transactions: the social conditions and moral beliefs that shape how transactions unfold, the ways that people make sense of their purchases, or how the exchange of particular commodities become morally contested. Fourcade (2012, p. 1056) describes how this Zelizerian shift toward "concrete transactions as the unit of analysis, rather than some putative market, or market actors... demonstrat[ed] (in a devastatingly effective way) the relevance of social context." As fruitful as this approach has proven to be, however, this focus on transactions has led scholars to neglect how the production side of the market is itself structured by inequality in ways that shape the moral identities of those working within it-leading to producer-differentiated market segmentation (see Anteby 2010, p. 607 for a similar critique).

In this article, we examine the perspectives of producers of goods in an illicit market. We focus on their moral understandings not of specific transactions, but of their longer-term participation in the market and the identity projects that they pursue through this work. This shift in focus-from the moral underpinnings of particular commodities and exchanges to those of production processesallows for a more thorough examination of the role of social inequality in organizing the market. In the next section, we harness evidence in support of this approach from a diverse array of subfields, from ethnographies of workers in illicit markets to analyses of scientists in academic and industry laboratories. Together, this work shows that the class-stratified experiences of workers in unequal markets leave durable imprints on their moral sensemaking and resultant economic action. At the end of this section, we advance a theoretical model for integrating these insights into the moralized markets literature.

\section{Social Positioning and the Moralization of Work}

In a market, producers and sellers construct moral claims and symbolic boundaries around their work, in order to maintain their own legitimacy and reputational advantage (Abbott 1988; Anteby 2010; Larson 1979). Groups of workers mobilize such claims to compete with others who might encroach on their jurisdictions, and the claims themselves often invoke the unique perspectives afforded by the groups' institutional, geographic, or socio-economic positions within the markets. The ways that different groups of producers justify their economic activity - particularly in morally contested markets - provide insights into their distinct regimes of worth and professional identities (Boltanski and Thevenot 2006; Shapin 2008).

In illicit markets, workers positioned at opposite ends of economic and professional hierarchies offer different moral accounts of their work and of their own role in these economies. In San Francisco, street prostitutes intentionally police boundaries between "living" and "working" by avoiding kissing their clients, whereas higher-end escort services offer "the girlfriend experience," cultivating a sense of authentic emotional connection and offering gestures of intimacy beyond erotic sexual acts (Bernstein 2007). The street prostitutes' identity projects strictly demarcate the work they do from the people they are, whereas the escorts work to blend these two identities as a way to separate themselves from those who "just sell sex." In New York, indoor-based sex-workers likewise morally distance themselves from those working outdoors, whose work is laced with shame and 
danger, and adopt an agentic professional identity and careerist orientation to their trade (Murphy and Venkatesh 2006). In the illegal drug trade, young street dealers enact self-identities of heroes who protect women and children from senseless gang violence and of loyal workers who would go to jail to avoid snitching to the police (Karandinos et al. 2014). In contrast, elite drug smugglers enact selfidentities as businessmen involved in rational transactions, criticizing others for "shady associates" and justifying their work as providing a commodity that people eagerly seek (Adler 1993).

The status of markets can sometimes shift from illicit to licit, as previously illegitimate trades become legalized. In such cases, actors often work to distance themselves from the past stigma of their profession. In the trade of cadavers, academically-housed professionals with doctoral degrees work to maintain an identity of altruists pursing "higher goals" while portraying their competitors, who lack both advanced credentials and institutional affiliations, as self-serving, unethical outsiders who could taint their profession's reputation through an association with "body-snatching" (Anteby 2010). Medical marijuana advocates similarly differentiate themselves from those advocating for complete legalization by emphasizing their focus on improving palliative care (Dioun 2018). In portraying themselves as morally superior to others, both groups of workers are able to avoid stigma and "uphold and shape the legitimacy of the work performed" (Anteby 2010, p. 611).

Even within legitimate markets, such as the field of knowledge production, groups of workers - scientists, researchers, and technicians - articulate conflicting "moral economies of science" (Daston 1995), or claims about how science should be practiced, which practitioners are most credible, and what goals scientists should advance. These divergent moral claims often relate to differences in class standing or institutional affiliations. In seventeenth century English laboratories, where claims to scientific truthfulness were rooted in gentlemanly identity, "gentleman-masters" claimed all authorship and recognition for experiments that were performed (and often designed) by nameless "servants," who, being "nongentle," were perceived as fundamentally untrustworthy and immoral (Shapin 1994, p. 393). By contrast, in nineteenth century English and French laboratories, where claims to scientific credibility were based around the ideal of objectivity, assistants were believed to be more trustworthy observers than their scientist employers (Daston 1995). In both cases, laboratory actors' moral claims to credibility were rooted in their social class identities, and these moralized class configurations in turn influenced the practice of science itself.

Institutional positioning, too, influences the moral frameworks articulated by different groups of actors in the scientific field. In the late nineteenth century, professional geologists and physicists articulated a moral identity centered around "applied science" and distanced themselves from the "scientific aristocracies" of university scientists who prioritized abstract theorizing over the public good (Lucier 2009). The university scientists conversely articulated a moral identity centered around "pure science" and disparaged "swindlers" and "charlatans" who prioritized capitalist pursuits over the advancement of knowledge (Lucier 2009). A similar distinction was apparent in Shapin's (2008) study of American scientists in more recent decades: whereas knowledge production was insulated from market influences for much of the twentieth century, beginning in the 1970s, science was increasingly viewed as an entrepreneurial venture with legitimate commercial potential. In this context, a moral fault line emerged between the university, which espoused "traditional academic virtues" such as intellectual purity (rewarded with modest financial compensation) and industry, which celebrated entrepreneurial spirit and commercial success. 
These studies show that across a diverse array of markets, producers and sellers' professional identities and moral frameworks are shaped by a range of factors, most notably their social class positions and institutional affiliations. This research suggests that markets are differentiated not only by social and cultural distinctions between consumers, but by moral distinctions that emerge from inequalities among producers. In the present paper, we seek to integrate the insights gleaned from this research on market workers with the moralized markets perspective.

In particular, three insights from this body of work strike us as most salient. First, this work shows that producers' moral understandings differ markedly depending on where they are located within institutional fields and social class hierarchies. Second, this work shows that producers' moral understandings of the market cohere less around discrete transactions, and more around their own enduring professional identities as workers in the markets: who they are and how they are different from other workers, what they hope to achieve in their careers, and how their work intersects with other domains of their life. And finally, this research suggests that the moral distinctions that producers articulate are central in shaping their habits of production, including what they do and avoid doing, what elements they strive for in their products, and how they manage interactions with other market participants. As such, the products and services in the market are indelibly shaped by these producer-level moral frameworks.

These three insights lead to the following model for how producers' moral sense-making shapes markets: (1) Workers occupy distinct class positions and operate within hierarchically organized institutional settings. (2) These unequal social positionings lead workers to form moralized professional identities and position themselves as distinct from other market actors, thus justifying their own participation while deriding others. (3) These identities and distinctions influence their orientation to the market itself - whether they view the market as fundamentally immoral, amoral, or moral - and how they define norms of professional conduct. (4) These moral frameworks subsequently shape their behavior in the market and lead to differentiation of products and services.

\section{Universities as Unequal Institutions}

Academic institutions are not only sites of knowledge production; they have long helped higherstatus groups to further consolidate and reinforce their dominance (Bourdieu 1996; Karabel 2006; Armstrong and Hamilton 2013). Economically and culturally privileged students experience a sense of "fit" between their own cultural capital and the organizational culture of their campus, and feel at ease when interacting with institutional structures and campus gatekeepers such as faculty and student leaders (Lee 2016; Rivera 2016). For these advantaged students, academic work, campus social dynamics, and post-graduate job market transitions often require little effort (Armstrong and Hamilton 2013; Jack 2019). By contrast, students from marginalized backgrounds face numerous challenges in navigating university cultures. They enter universities without knowing the tacit rules of the game, often struggle during their studies, and emerge from universities feeling socially alienated and professionally unprepared (Jack 2019; Lareau 2015; Lee 2016). Specific institutional actors - teachers, advisors and peer mentors - can act as "cultural guides" for these underprivileged students, helping them to navigate unfamiliar academic cultures and contributing to their academic and professional success (Lareau 2015).

Much like most institutions across various social contexts, universities are organized into 
rigid status hierarchies. As the market of universities becomes increasingly diversified, boundaries between tiers can grow more salient, as happened in the United States (Shavit, Arum, and Gamoran 2007). On the ground, these status boundaries are often reinterpreted as different valuations of curricular content: more elite universities prize theoretically-oriented scientific and intellectual pursuits, whereas less elite campuses instead tend to emphasize professionally-oriented administrative and entrepreneurial pursuits (Bourdieu 1996; see also Shapin 2008). These different systems of valuation across campuses, in turn, shape the cultural perspectives of students who pass through them (Binder and Abel 2018).

Together, these insights elucidate how the moral outlooks of researchers in Kampala are structured by both inter-institutional status distinctions and intra-institutional social class hierarchies. The two campuses in this study differ considerably in reputation and prestige: Technical University is lower ranked and less renowned than top-ranked Flagship. These different hierarchical positionings within Uganda's academic field, in turn, shape the universities' institutional cultures: At Flagship, academic merit and knowledge production are emphasized, reflecting the university's distinguished position and longstanding reputation as a regional destination for higher education, whereas at Technical, entrepreneurial energy and business acumen are instead prized, reflecting the university's history as a specialized vocational school. Within both universities, researchers who experienced a better "institutional fit" with their university adopted professional identities and moral justifications that were consistent with, albeit distorted reflections of, the dominant institutional cultures surrounding them as students. On the other hand, those whose economic, social and cultural capital did not fit with their institutional environments developed identities and moral frameworks that drew directly from their experiences of alienation and exclusion. These divergent experiences, in turn, shape researchers' attitudes toward their work and how they organize their business practices.

\section{METHODS}

This study draws on ethnographic observations and interviews that were conducted by the first author as part of a larger longitudinal study about university graduates living in Kampala. ${ }^{3}$ Data collection around Technical University was primarily located in the nearby student neighborhood of Banda. Data collection around Flagship University was evenly spread around the three neighborhoods where students tend to live, as there is no concentrated student neighborhood around this campus.

Ethnographic observations in these locations were conducted about one to three times per week during eight months of fieldwork in 2018. These trips involved walking around the campuses and neighborhoods, visiting small businesses catering to students (including the research shops), informally conversing with shop owners and residents, touring student residences and speaking with their occupants, and attending campus events and extracurricular activities. Since the research market is more overt in Banda, observations there also included a formal tally and mapping of the neighborhood's supply of research shops.

Interviews with researchers in the illicit market were arranged by three Ugandan key

\footnotetext{
${ }^{3}$ Although in this article we focus explicitly on the perspectives of the researchers, our analysis was also informed by this larger study, which included interviews with recent graduates (about one quarter of whom admitted to hiring researchers for their final project), as well as by informal conversations with faculty colleagues at Flagship, where the first author was a visiting scholar.
} 
informants who previously attended Flagship and Technical universities. Two of the key informants previously worked as researchers themselves; for the first several interviews in each location, one of them was present and asked additional questions based on these past experiences. The study began in Banda, and initially targeted graduates working in all student-oriented businesses. After observing how student research permeates social and economic life in Banda, we later adjusted the sampling to specifically investigate the research market, including more researchers around Banda as well as researchers near Flagship University.

Altogether, 41 formal interviews with 36 researchers were conducted across both locations. In Banda, 20 researchers were interviewed, 18 of whom had attended Technical University. Over time, the first author encountered people she had interviewed during past visits while walking around the neighborhood, and they offered brief updates about their lives and reflections on recent happenings, which she wrote down soon after leaving them. At their invitation, she also revisited five researchers for follow-up recorded sessions, for a total of 25 recorded sessions with Banda researchers. At Flagship, a total of 16 researchers were interviewed, 14 of which had attended Flagship themselves. These interviews were similar in format to those conducted in Banda, with the main difference being that sampling for this batch of interviews was limited to people working in the research market.

All interviews were conducted in English, in locations chosen by the researchers, typically their shops or homes. They included open-ended questions about the researchers' time at campus, their trajectories since graduation, the details of their business and how they conduct their work, and how they felt about their current circumstances. The recorded portion of the interviews ranged from 35 to 70 minutes, with an additional 15 to 30 minutes of informal interaction before and afterwards.

The major distinctions between the three groups' moral orientations first became apparent during data collection, but the connections between these moral orientations and other elements of our study (notably, their social class positionings and their workplace practices) emerged during subsequent analysis, through coding and memo-writing. The interviews were transcribed and coded with a focus on broad themes related to the moral frameworks that researchers used to make sense of and justify their work, their educational backgrounds and experiences entering the market, and their current work situations.

After finishing coding, we wrote detailed memos about each researcher, and then assigned them to one of the groups. In this assignment process, we paid most attention to their descriptions of how they defined good work and bad, how they felt about participating in the illicit research market, and how they viewed other market participants - including other researchers in the market, their student-clients, and the supervisors. ${ }^{4}$ We then wrote longer memos about each of the campus environments, and, as a final step, about each of the three moral frameworks. These individual and group-level memos were crucial for allowing us to see how the moral distinctions we had noticed during fieldwork were rooted in their campus experiences, their current market positions and their

\footnotetext{
${ }^{4}$ For 33 of 36 respondents, the process of sorting them into groups was straightforward, because their answers primarily invoked one the three sets of moral understandings (though some, of course, offered more detail than others). We were unable to categorize the remaining three - one interview was unexpectedly cut short, one was conducted at the very start of the study and focused mostly on basic descriptions of the research field, and one respondent simply did not have much to say about the topics listed above.
} 
professional identities.

\section{OVERVIEW OF THE RESEARCH MARKET}

\section{The Universities and their Institutional Cultures}

Flagship University, founded during the colonial era and once known as the "Harvard of Africa," remains Uganda's most prestigious university and is currently ranked fifth in Africa (Times Higher Education 2021). Academic research occupies a fundamental part of the university's identity.

Foreign research contracts are vital sources of funding and institutional acclaim: bulletin boards boast of specific internationally-funded research activities and foreign academics frequently visit the campus. Within this academically-inclined institutional culture, the student research market poses a serious moral threat, and researchers working near this campus believe that Flagship faculty view the research market as a problem to fix. They described supervisors trying to catch students and punish them for outsourcing their projects, and differentiated this level of concern form the more accepting attitude espoused by Technical faculty.

Situated on a verdant campus with colonial-era buildings, Flagship is located within walking distance of the old downtown area of Kampala. As such, no neighborhood near campus caters exclusively to students. The surrounding neighborhoods are frequented by faculty, families, and businessmen, and student hostels are nestled between apartments and shopping malls. Services catering to students are too small-scale to occupy formal storefronts in this business district, and are instead crowded into tiny spaces: a desk in a hallway may sell inexpensive snacks, students offer hairstyling out of their bedrooms. Student life is more diffuse (and integrated into a centralized urban zone) and faculty are as likely to walk through a given neighborhood as the students they teach.

Due to Flagship's central location, its market for research services is hidden in plain sight. Research shops around Flagship are located both on and off campus. Off campus, researchers work in one-room storefronts on dusty roads behind main streets, and on campus, in stalls tucked into the ground floor of residence halls or in trailers near classroom buildings, slinging power hookups from up the road for their computers and printers. Most advertising for student research at Flagship happens far from the shops themselves. If a shop hung a sign proclaiming that research was done there, then faculty and university staff could close it down. Instead, researchers advertise using flyers stapled to campus trees and bulletin boards (Figure 1) or through "word of mouth," handing out business cards to past customers and accepting overflow from other shops.

Technical University, the second largest public university in Uganda, is well-regarded but considerably less prestigious than Flagship. ${ }^{5}$ Technical was created in 2003 by merging a college for

\footnotetext{
${ }^{5}$ Technical is not included in any international university rankings, and ranked sixth (with Flagship first) in a recent local ranking of 45 Ugandan universities (uniRank 2020). "Cutoff points" for national university entrance exams are more commonly used by Ugandans to compare universities to one another. For a given course, more prestigious universities have higher cutoff points, which designate the minimum acceptable score for a particular course. We selected 10 courses offered at both universities and compared the cutoff points for 2019-2020. All 10 subjects had higher cutoff points at Flagship (mean: 32.75) than at Technical (mean: 21.10). These entrance requirements correspond to how faculty and students situated these universities in Uganda's higher education hierarchy, with Flagship on top and Technical in a middle-ranking position.
} 
teaching and a polytechnic for engineering and other trade sciences. The university has since expanded to offer other subjects, but remains focused around engineering, teaching, entrepreneurship, and vocational studies.

Technical retains its applied and service-oriented identity and lacks the academic ethos of Flagship. Entrepreneurship and business acumen are central to its campus culture, whereas research is less emphasized. Signs celebrate departments' connections with local businesses, and campus clubs encourage students to learn to be a barista, to make and sell honey, and to pursue other ventures. At Technical, faculty seem more likely to have contracts with local industry or Ugandan governmental projects than with foreign researchers. Within this entrepreneurial culture, the research market is less of a moral affront, and researchers working around Technical believe that faculty there view this market as something to tolerate. While professional researchers may not be celebrated, they are more openly acknowledged, and some faculty were even described as actively supporting their work.

Technical is located on the outskirts of Kampala. Nicer suburban neighborhoods lie to the west and north of campus, where streets are filled with new gyms, restaurants, and nightclubs. The vast majority of Technical students live on the other side of campus, in Banda, a densely packed and highly stratified neighborhood filled with students and recent graduates. From inside Banda, the rest of Kampala feels quite far off. The shops are all designed to meet the needs of students - chapati stands, money lenders, second-hand clothing stalls, and a dizzying array of research shops.

Unlike in the neighborhoods around Flagship, researchers in Banda occupy the center of commercial life. Student life is more concentrated (and segregated from the rest of the city), and faculty and university staff rarely walk through Banda. Research shops proliferate in Banda and researchers prominently advertise that they do student research. The most established shops have large, colorful signs, and the smaller shops tape printed paper to their doors (Figure 2). Figure 3 provides a sense of the dominance of shops advertising research in the neighborhood. ${ }^{6}$ The densest concentration of research shops is found on the two main streets of the neighborhood (indicated by the purple circle in the map), where entire rows of storefronts sell only research.

\section{The Exchange of Student Work}

Final year research reports are required across most social and natural science, business, and engineering majors at both universities. These reports include five chapters and vary in length from 40 to 120 pages. Researchers are typically hired to do entire projects. During a period of about three months, student-clients serve as conduits between their researchers and their faculty supervisors, bringing the researcher's drafts to the supervisor, taking the supervisor's edits back to the researcher, submitting the revised draft, and orally defending it to the supervisor.

According to the researchers, student-clients tend to come from wealthy or middle-class backgrounds and are more likely to be women than men. Most student-clients are in bachelor's degree programs, though a few are graduate students. Undergraduate projects range in price from \$50 to $\$ 120$; researchers described setting prices according to the nature of project, attributes of the

\footnotetext{
${ }^{6}$ A similar mapping exercise was not possible for the research shops at Flagship because these shops do not openly advertise their research services on their storefronts.
} 
research shop, and their assessment of the student-client (pricing varies across the three groups, as described below).

The faculty supervisors' requirements determine the intensity and rhythm of the interactions not only between themselves and their students, but also between the student-clients and their researchers. While most supervisors only meet with students at the beginning (to select the topic) and the end (to defend the project) and make only one round of "corrections," more demanding ones require in-person meetings about each chapter and multiple rounds of revisions; still others do not meet with their students at all. Before consultations with the supervisor-especially before the final one- the researcher provides the student-client with enough background knowledge about the project so that they can convince their supervisor that they produced the work themselves. If the studentclients make too obvious an error during these consultations, the supervisor might suspect they cheated and make them start over with a new topic. The faculty supervisors, then, can be thought of as shadow third participants in these market exchanges, even though the researcher never meets or directly corresponds with them.

Outsourcing student research is against the official rules on academic misconduct at both universities. Cheating and plagiarism can result in students' suspension or expulsion from the university; if plagiarism is detected after graduation, academic degrees can be revoked. Almost of all researchers reported working with student-clients who faced sanctions because their supervisors accused them of hiring a researcher; one researcher estimated that this happens about five percent of the time. In most of these cases, the supervisor asked the student to start over with a new topic of the supervisor's choosing; when researchers continued working on these reassigned research projects, they sometimes negotiated higher fees to account for the additional labor. In two cases, the accused student-client failed the research requirement and had to repeat it the following year.

Some researchers also described supervisors trying to prevent students from outsourcing their research work, before it happened. For example, John ${ }^{7}$ described how one supervisor demanded to see the "clearance stamps" that indicate official permission to collect data, to ensure the student had actually gone to the field. Other supervisors insisted on assigning topics, without giving the student a choice - this was described as a way to ensure that students didn't choose a topic that a research shop had requested. Researchers also reported that one department at Technical had recently moved away from the research requirement altogether, replacing it with internships. Still, attempts to curtail the practice by faculty seemed largely ineffective. In his newspaper article on the practice, Kaija (2017), a lecturer at Flagship, quoted several university faculty and administration officials who described deliberate efforts to punish students caught in the act, but felt powerless to intervene in the broader market.

\section{CLASS TRAJECTORIES AND INSTITUTIONAL POSITIONINGS}

This section introduces the three groups of researchers, and focuses on the interactions between their social class trajectories and their positionings vis-à-vis the two university cultures. As topperforming, serious students at Flagship, Knowledge Producers fit relatively well within the dominant campus culture emphasizing research excellence. As socially-connected business students

\footnotetext{
${ }^{7}$ Pseudonyms are used to protect researchers' anonymity; Information about each researcher quoted in the manuscript is provided in Appendix Table A.
} 
at Technical, Entrepreneurs fit relatively well within an institutional culture valorizing industry connections and business acumen. By contrast, as financially precarious and socially isolated students, Educators were alienated from the dominant cultures on both campuses. We describe the three groups' backgrounds and campus experiences, their routes of entry into the research field, and their current circumstances and market positions (this information is summarized in Table 1).

\section{[Insert Table 1 here]}

\section{Knowledge Producers}

\section{Campus Experience: Brilliant Students at Flagship}

Of the eleven researchers that we classified as Knowledge Producers, nine studied at Flagship and two at Technical. While no researchers in this category described affluent childhoods, their families were able to support them throughout their education and three Knowledge Producers received government scholarships, which provided for their university fees and living expenses. Most (8/11) grew up in or near Kampala, or in one of the other cities in Uganda, suggesting a more advantaged background than the Educators, who were mostly raised in rural villages. All but two described having been identified as clever by their teachers in primary or secondary school. Three served as "head boys" or "prefects" in secondary school and several others participated in organized scholastic activities, such as debate. These academically-oriented, urban backgrounds allowed them to subsequently excel at Flagship.

When recalling their university experiences, Knowledge Producers consistently claimed that they actively sought out opportunities to develop skills and deepen academic knowledge. Among researchers in this group, the most popular majors were social sciences (five) and information studies (three). They received top grades for their academic work and often described themselves as "excellent", "brilliant" or "serious" students; these descriptions reflect their elite campus culture's celebration of academic merit. All of them also recounted going beyond what they learned in the classroom, especially in terms of cultivating research skills. Gerald, for instance, volunteered for multiple private organizations outside of campus in order to gain research experience. Derrick worked at an on-campus research center and read the journals stored on the shelves there: "You can get a lot of knowledge and see how people make books, journals.[...] So...looking through them, I'm like how can someone write a very good journal with very nice findings? I studied them until I could produce a report like those." During these visits, Derrick also spoke with graduate students and staff about the research process.

All Knowledge Producers completed their own final year research projects, which most described as a positive experience. Ronald said, "I finished early when almost everyone finished late, after the deadline. And I knew I was going to get an A one for timekeeping, two for good work, quality work, I completed a lot of good research." Several described receiving excellent grades for this work and being complimented by their faculty supervisors in front of peers and other instructors.

\section{Entry into the Research Field: A Stalled Progression}

Knowledge Producers' reputation as high-performing students often led their classmates to ask them for help with their research projects. John recounted how two friends approached him: "Before they could move to their professors they would come to me for corrections. Because while I was at 
campus I was a serious student. Like, everyone would be like, if John is doing something, trust me that he's going to get a top grade." Later on, Knowledge Producers like John would capitalize upon this reputation among student-clients to develop their research businesses. At the time, while finishing their degrees, they aspired to enter licit research markets, doing evaluations and marketing for formal organizations. Kizito described how he taught himself data analysis in order to fulfill this "dream" of working for non-governmental organizations:

My dream was to be hired into research when I finished campus. I always use YouTube - so I taught myself how to use SPSS, so I could do data analysis, of course not at student level but at $N G O$ level. I've always tried to get more knowledge about data analysis because I really feel research is what I really want for my life.

Like Kizito, most Knowledge Producers did not intend to do research for students when they first graduated. Many imagined that their investments in research skills would translate into researchoriented jobs for private organizations. But over time, as their applications yielded no callbacks, they fell back on those same research skills to write student projects. Moses described the disappointment he felt entering this field: "Before we went into [student] research, we saw that we had lost hope-we didn't have what to do. We tried looking for jobs online, data entry, analysis, but all in vain, there was no job, no employment."

\section{Current Market Position: Overqualified and Under placed}

The research shops of Knowledge Producers were smaller than those of Entrepreneurs, but were more centrally located than Educators' and had nicer computers inside. All but two were located around Flagship, so signs outside their shops advertised printing, grant writing, and other services besides research (which they devoted nearly all their time to). Compared to Educators, their clientele were roughly similar in size, ranging from 20 to 55 student-clients per year, but they earned more per customer (Table 1). Three Knowledge Producers described working with some master's students, but most worked only with undergraduates. They mostly worked alone, with some temporarily employing research assistants when asked to collect data in the field for a given project.

Knowledge Producers described feeling stuck in student research, overqualified and under placed. Despite performing well at Uganda's top-ranked university, several Knowledge Producers expressed dissatisfaction with their credentials - specifically, that their courses, being mostly social science and information science related, were not considered relevant for doing research professionally. Echoing Flagship's cultural emphasis on research and knowledge production, they yearned to earn a living doing "real research"-working for NGOs and private companies. A few mentioned trying to secure scholarships or other opportunities to pursue a master's degree or postgraduate certificate, which they hoped would better translate into opportunities for future jobs. All of them were actively networking with and applying for research-related entry-level jobs. Joel explained this desire to leave the student research market in the following way: "Because [real research] is using similar skills to what I'm doing here, but it is open, people would be knowing that I am doing that work. And you can have access to the better data when you work for the companies doing the programs. So I think it will be more satisfying for me." 
At the time of data collection, these efforts had yielded little success. A few Knowledge Producers reported occasionally doing small short-term NGO or business contracts, but this work was not steady and did not pay the bills; thus they all continued doing student research. Accordingly, they expressed frustration that their efforts had not thus far moved them much closer to their "calling" (Kizito) and "dream" (Ronald, Joel). John was an exception: a month before our interview, he had landed multiple data analysis contracts from a hospital nearby, and had subsequently decided to only do the more technical chapters of student research, rather than the entire project. If students asked him to complete their full report, John said, "I tell them no I don't have time and specifically now I've changed to only doing data entry and analysis, since I do research now for big organizations. So I'm seeing that to be a very good trend to move on from doing [research] for students."

\section{Entrepreneurs}

\section{Campus Experience: Well-connected Business Majors}

Of the twelve researchers classified as Entrepreneurs, nine studied at Technical, two at private universities in Kampala, and only one at Flagship. Entrepreneurs varied somewhat in their social class background - some, like Rogers and Austin, came from very wealthy families, whereas others hailed from middle-class backgrounds, such as Kato, whose father worked as a secondary school teacher. However, unlike Educators, none of the researchers in this group described being raised in poverty and all had parents or relatives who paid their university fees and living expenses. Several mentioned attending highly-ranked secondary schools, where they gained cultural capital that allowed them to fit in with their peers at campus and connect easily with their professors.

Most Entrepreneurs completed business-related courses: five studied business or business communication and another five studied finance or economics. Several Entrepreneurs claimed that these courses facilitated their success in building research shops, equipping them with "businessrelated skills" (Emmanuel) and lending them a "business orientation" (Ivan). When describing their shops, Entrepreneurs also used "business-speak" - they called them "research companies" (Kato, Ivan, Fred, Wamala) or "consultancy firms" (Emmanual, Emerson, Fred, Austin, Kato) rather than "research shops" or "stationary shops" like the other two groups.

When recalling their undergraduate experiences, Entrepreneurs emphasized their social networks. In Kampala, social connections are known to strongly influence post-campus trajectories, regardless of whether a graduate starts a business or applies for jobs. By emphasizing their many friends and informal connections, Entrepreneurs were asserting a privileged status on campus. Rogers attributed his connections to a prominent post he held in student government: "I knew many people, I was a guild council representative... You know, I was a leader.” Kato underscored the longlasting connections he built with faculty: "I've always interacted with many of those lecturers at Technical. Some of them are still my friends."

Like Knowledge Producers, Entrepreneurs described their campus experiences in a positive light. Whereas Knowledge Producers highlighted their top grades and successful research projects, however, Entrepreneurs instead emphasized their social connections and extracurricular activities. Entrepreneurs were less likely to mention their grades or being known as top students in their classes. Most Entrepreneurs also admitted to hiring a researcher for their final projects, and only two 
described completing them alone. These differences reflect the fact that both groups emphasized markers of success that were valorized by their respective campus institutional cultures. Whereas academic success and independent knowledge is celebrated at the prestigious Flagship University, savvy business sense and interpersonal skills are valued over class performance at mid-ranked Technical University.

\section{Entry into the Research Field: A Conscious Choice}

Unlike Knowledge Producers, most Entrepreneurs described entering the student research business by choice. Many worked in the formal sector and became frustrated by the low pay, lack of advancement opportunities, and difficult working conditions characterizing entry-level jobs in Uganda. Austin describes how he was inspired to quit his job and start a research business:

I was working with [a private marketing company]... Then I decided to leave, I saw the money for the job was less. Statistics, the course I did, is all about research so I said I can start up something around that and that is how I took it on. I also had a friend who used to do it and he is the one who inspired me. He was making good money."

The fact that they emphasized the potential for profits and better working conditions shows that Entrepreneurs were initially motivated by what they viewed as a viable business opportunity, unlike Knowledge Producers, who were driven to this work in pursuit of opportunities to conduct research.

Entrepreneurs often recounted entering the student research market through reconnecting with friends who ran successful research shops and invited them to help out after hearing about their work experiences. When asked why he quit his job and started a research business, Emerson said: My [friends] would meet me around town, because I had many friends at campus. And they would ask me "Where do you work?" I would tell them I work with British Council, we do data entry and analysis. Then they would ask me "Can you help somebody in data entry, somebody who is just a student?" Rogers similarly described how temporarily working at his friend's shop became a permanent occupation: "I saw that it can be a good business. I liked it and my friend was well established, he had so many people coming here. And I saw that I could use the connections I made at campus for this work. " Importantly, in explaining their choice to enter the field, both Emerson and Rogers mentioned their extensive social networks - how they had "many friends" and could "use the connections" they had made while on campus.

Whereas Knowledge Producers and Educators tended to start out modestly, Entrepreneurs usually had the means to build larger shops right away, and their experiences entering the field were relatively seamless. As Emmanuel stated, "I started with four computers that I got second hand. Then furniture, we are talking about 700, then rent. Actually, my place was a little bit big." Entrepreneurs utilized various resources to start their businesses, including financial help from family, past earnings, and partnering with friends who owned existing shops.

\section{Current Market Position: Centrally Located Shops with Many Customers}

Ten of twelve Entrepreneurs worked in Banda, one worked in a commercial neighborhood far from both campuses, and one worked in Wandegeya, the oldest and most established business area around Flagship. Most of their shops were located in the center of Banda, on the main road near the campus 
entry gate - the most desirable space in the thriving research market around Technical. Their businesses were larger and more established than those run by Knowledge Producers and Educators, with glossy, professionally-printed signs advertising research outside and multiple computers and printers inside. Although we never saw more than three workers in their shops, Entrepreneurs often boasted larger staffs of ten to twenty assistants. They also claimed larger pools of student-clients, which most estimated to exceed 100.

Several Entrepreneurs described working with both graduate and undergraduate students, and two worked mostly with graduate students. As Ivan explained, graduate students were more desirable customers because they paid substantially more (about four times as much) and because they showed "growth" in the business:

Ivan: So I was in Banda for close to around two three years... at first I was associating with [undergraduate] degrees, then masters started coming in and still I could handle them because I had this good ground of undergraduate. Now in fact of late I am now doing mostly for masters.

Interviewer: Why did you move on from undergraduate?

Ivan: Okay the pay is a factor but there is, can I call it growth, you are moving from one step to another.

Entrepreneurs, like Emerson here, also described easily getting referrals, without needing to market themselves: "I have a reputation, people in Banda know me. I don't advertise because [research] is a problem for all students. Once they realize that they can get assistance, you will find the whole group coming to you." Four Entrepreneurs also mentioned lecturers directly referring students to them, underscoring their central social positioning within Banda's research field.

\section{Educators}

\section{Campus Experience: Struggling and Isolated}

Educators evenly distributed across the two universities: out of ten Educators, five attended Technical, four Flagship, and one a private university in Kampala. Educators received degrees in various fields, including information technology, library sciences, liberal arts, and education; their majors tended to have less stringent entrance requirements than those of the other two groups (assessed using campus "cutoff points", see footnote 4).

Educators' time at campus was characterized by struggle. All came from poor families and most came from villages where their parents worked as subsistence farmers and had no means to help them financially while they were at school. Their lack of economic, cultural, and social capital translated to poverty, academic difficulties and social isolation at campus. For example, Mugisa almost did not graduate due to several failed grades (or "retakes") and his family's inability to contribute to his tuition: "I struggled a lot while at campus. I almost didn't make it through as I had several retakes and money for tuition was often not coming until the end. When tuition was not there, the lecturers chased me from class. So I could not sit for exams." Tonny, who had never lived outside of his village before, felt that he stuck out because he wore shabby clothes and lived in Bwaise, a slum that became uninhabitable when it rained. He recalled feeling judged and misunderstood due to these differences between him and other Flagship students: "I had so many 
challenges from home but also challenges related to the other students. There are people who see you and they think perhaps you may not pass which is not the case, even when you try to explain your case they do not want to give you time, they do not want to understand you." Educators also reported difficulties interacting with professors and passing classes; as Lawrence recalled, "I never felt fit [to speak in class] because of where I come from. I went to these village schools, [where] we didn't wear shoes. My marks were usually poor."

These challenges peaked during the final year research requirement. All Educators struggled with this assignment, and three, like Steven, almost failed the requirement: "It was too hard for me because I didn't have the computer and I also didn't have any skills in data analysis. My supervisor made me start over after the first research I wrote, it had many problems." Other Educators reported struggling through multiple rounds of corrections and being unable to complete the assignment themselves, despite devoting more time to it than their classmates. Marvin said he would have failed his research requirement, had a friend not referred him to a researcher and covered the cost. This led Marvin to sympathize with other student-clients who struggled with their research requirement:

When I had to do research, I almost couldn't get through it. I tried on my own but I found that I didn't know anything about data analysis or writing the objectives, methods, results. My friend referred me to a certain person who was doing this work, and he helped me with the data analysis and then I was able to write the rest of it. That's when I first came to see how the work is needed by students. It's when I learned what this research business is.

\section{Entry into the Research Field: Climbing Out of Precarity}

Unlike Knowledge Producers, who developed reputations as skilled researchers, Educators were known among their peers for their work ethic and sympathetic demeanor. Having struggled as students, they possessed both empathy and an ability to explain things simply. Thus, despite their lack of research expertise, other students approached them for help. Mugisa explained that he had often been seen working on his research in the public computer lab, because he lacked his own computer. This led others in his course to ask him for help, and these favors slowly evolved into a business:

At that time I was doing it freely as a favor, free of charge. But later [...] they had their colleagues who were still around the university and who were also struggling with research and they referred them to me. The fact that I had finished and I had not gotten a job yet, I started charging them some little money.

Educators often described experiencing abject poverty between graduating and subsequently entering the research market. After barely passing his own research requirement, Otim was living on the street, destitute but determined to remain in Kampala, where the jobs are, rather than going back to the rural district where he grew up. He got a typing job through a chance encounter with a stranger, which led to research: "I had passion for computers, you get it? While I was here at campus I fell into love with the computer. And that guy, he was weak in computer and so he said, can you come and help me in my shop? And so I did typing and secretarial work, and then slowly started doing research." Without much prior training, several Educators, like Otim, first learned the trade 
through doing less lucrative typing work. Godfrey recalled how students brought research projects to the shop he worked at: "Every time I could be typing that work for them. As I typed, I would be reading it and testing my capabilities. From there, I realized that I could also produce research." Other Educators entered the field gradually, supplementing their income with short-term jobs often involving manual labor and requiring no advanced education. Over time, they expanded their clientele until they could support themselves exclusively (if precariously) through research.

\section{Current Market Position: Peripheral and Financially Strained}

Six Educators worked in Banda and the remaining four around Flagship. Their shops were typically small, with only one or two computers (see Figure 4 for one example of such a small-scale shop). In Banda, most Educators' shops were located in "Lower Banda," down the hill and in the slum area. Three Educators worked from home, meeting students in the shops of friends. They typically did between 15 and 40 research projects per year, and none had done graduate-level research. All were struggling financially and several were uncertain that they could make next month's rent.

About half of this group described needing to subcontract their student-clients' data analysis to others because they lacked experience with data analysis software, decreasing their profit by about a third. As Steven described, "Research where maybe there is a lot of mathematics, using formulas and algorithms, those ones I have some people that I consult... In some schools, they use statistical software like SPSS or Stata, for those I need to consult with others." In these cases, he subcontracts the data analysis to other researchers, but writes the report himself. In this way, Educators continued to experience the after-effects of their difficulties in learning to conduct research as undergraduates.

\section{PROFESSIONAL IDENTITIES, MORAL FRAMEWORKS, AND MARKET ACTION}

The institutional and class differences described above directly influenced the professional identities and moral justifications that researchers leveraged in making sense of their trade. Around Flagship, Knowledge Producers mobilized an identity of diligent scientists that echoed the elite university's emphasis on academic excellence, and characterized the student research market as immoral, violating the sacred purpose of science. Around Technical, Entrepreneurs marshalled an identity as savvy businessmen, which echoed the mid-ranked university's emphasis on industry connections and commercial acumen, and characterized the student research market as amoral, just a product like any other. Across both institutions, Educators developed an alternative identity as sympathetic tutors, emphasizing the universities' inadequate treatment of disadvantaged students like themselves, and characterized the research market as moral, providing necessary help to disadvantaged students. In what follows, after describing how the groups of producers constructed their own professional identities and demarcated themselves from others, we show that these identities and boundaries influenced their moral frameworks - how they defined the fundamental moral problem underlying the marketization of research and articulated norms of professional conduct. We then show that these moral frameworks shaped their workplace practices, resulting in distinct products and services (this information is summarized in Table 1).

\section{Knowledge Producers}




\section{Professional Identity and Moral Distinctions: Producing True Research}

When justifying their participation in the illicit market, Knowledge Producers emphasized their "passion" and "love" for research and dedication to pursuing the truth. They also highlighted the quality of the final products they delivered, rather than the benefits they provided to student-clients (as Educators did) or their business acumen (as Entrepreneurs did). When articulating his identity as a "researcher," Jacob explicitly set himself apart from other "businessmen" who lacked his diligence and credibility: "Me, I go to the field and I read and write the report from scratch. But these other shops in Banda, they just recycle... So, they aren't really researchers. They are just businessmen."

Derrick, too, drew a moral boundary between "big shops" that "just copy from past reports" and his shop that produced reports based on "real" information and "advanced" methods. His professional identity was based around continual self-improvement and the ability to produce credible work to counter a system that rewarded false information:

I am one person who always wants to do new things. I believe that every year I'm different because I read so much, I'm always improving[...] And also every year I try to improve on my statistics. So maybe last year I did a logistic regression, this year I can add to that and try to do a multicollinearity test. Because that is my passion, research [...] Maybe the report I make will have someone else's name on it, but inside the information is real, so the research will still be helping in some way.

For Derrick, even when others received credit for their contents, his reports still held potential societal benefits, because of their credibility. Several other Knowledge Producers similarly described feeling motivated by the possibility of influencing future readers. Kizito said he spent sleepless nights striving to obtain quality information because "You never know. One day someone may read one of the reports and it might influence them, they sit there in the library, and future students will read them, maybe even others could hear about them."

\section{Defining the Moral Problem: Fake Research and Entitled Students}

For Knowledge Producers, the moral problem underlying the illicit research market was that most student research was "fake" - either plagiarized or fabricated. This violated what they deemed the very purpose of research: to produce new information, and thus rendered the research market immoral. As Derrick stated:

I think that it is so, so bad that these [reports] are being printed and bound into books, they sit in the library but there is nothing inside - no information. Research is about building knowledge and sharing with others. The worst thing is when the contents are fake, because that knowledge is not there.

They also identified a secondary moral problem, more directly tied to the class structure of universities: students receiving undue credit for outsourced work and securing jobs requiring research skills. Ronald lamented how others were receiving reputational benefits for his work: "they will graduate and some people will think they know research. In actual sense they don't know anything, we are the ones with those skills. But they will get the jobs, because they have the right 
kind of background." Derrick also complained that outsourcing research prevented students from learning important skills, but did not prevent them from securing high-status internships.

Knowledge Producers placed the blame for these problems on the students who hired them. They frequently described student-clients as "lazy", and derisively commented on their clients' privileged class position, calling it, for example, the "comfort zone life." Kizito said that students were "not willing to really go an extra mile and read more... They just keep playing and chilling." John echoed this sentiment: "In Uganda, most children from rich backgrounds, they don't give attention to academics because they are relaxed in everything they do... When it comes to research they also don't have passion."

Whereas Educators claimed that student-clients would benefit educationally through working with them, Knowledge Producers made no such assertions. Several, like John, emphasized their student-clients' lack of motivation and claimed that students were singularly interested in graduating and, as such, they get "only the mark," with little learning involved. They were also frustrated with professors - not for their inadequate instruction, but rather for their inability to inspire students. According to Joel, lecturers' unserious attitudes enabled students to not take the assignment seriously:

I think if a lecturer was serious... then students can change, they will be inspired. But if the lecturer just says, you go and do some questionnaires, a student will just produce half-baked work and hand it in... But I know that if the lecturers were serious, students could also raise up and produce some sensible work.

\section{Norms of Professional Conduct: Intrinsic Motivation and Continual Self Improvement}

Persistent devotion — of time and effort — was central to Knowledge Producers' definition of good work. Since they construed research as a calling, they also emphasized the importance of intrinsic motivation. Gerald described how research and writing had become hobbies: "I don't only do it for money but I have passion for it. It's now like a skill and I also put it even in my hobbies ... when you keep on making research, you keep on reading more books of other writers, and it's very interesting." Many others in this group (including Derrick above) echoed this ethic of continual self-improvement through cultivating advanced techniques and competences.

For Knowledge Producers, doing research produced internal benefits. Moses, for example, said that it "keeps your mind focused" as it involves "extensive reading," "learn[ing] the crazy language, fancy terms" and "understand[ing] why certain things should be done." Kizito felt "excited" when he was commissioned to work on challenging topics, requiring primary research or in-depth reading of a new literature: "I look at it as a blessing to help me."

The lack of external validation was the converse of their emphasis on internal benefits; others receiving credit for their work aroused considerable frustration among this group. Indeed, even as Knowledge Producers appreciated the self-betterment they achieved through their efforts, they still yearned for broader recognition of their skills and achievements. Both Moses and Jacob described how the "brain" was theirs but the "name" was not. Moses looked for the silver lining to this situation: "even if they congratulate him, I will also have it at heart that surely the congratulations are for me, because it is my brain that knew how to do that work." Jacob, however, was more bitter about the exploitation of his potential: 
Those people always come use your brain, they pay you little but you work hard. Because you love what you're doing, you can't send away the job. You keep it, and you do it well. You do amazing research for that person... But then you find someone earns 5 million and you are there with your 400 [thousand] that they paid you.

Knowledge Producers also described feeling shame around their participation in the illicit market and a desire to conceal their work from others. Derrick stated that if he had a girlfriend, he would not "disclose anything related to this research... It is not work I can be proud of." When asked why, he replied that he gets no recognition for his efforts: "there is no way that you can say, me I did that work. So there is no respect." Gerald likened this desire for secrecy to that of a sex-worker: "I have never been a prostitute but I imagine when someone has to go for that ... you want to do the business but you don't want people to know."

\section{Products and Services: Credible Reports, Limited Student Engagement}

Knowledge Producers described their reports as having original literature reviews, real data sets, and more complex statistical methods than those produced by other researchers. To learn methods, some Knowledge Producers reported reading and analyzing data, even when there were no customers. Jacob said:

I don't believe in wasting time and there are no clients as of now. So what I do is download the Bank of Uganda data [from] last year ... I am using that dataset to try out new methods. So as long as I have the data and I can make some regressions, I can see if there are some correlations, try to do some projections, it can help me to develop my skills.

Derrick described perusing recent issues of international journals "to get the most up to date information" for use in future research projects.

On average, Knowledge Producers charged less than Entrepreneurs, but slightly more than Educators (Table 1). When determining the price for new student-clients, Most Knowledge Producers emphasized elements of the work itself - how far before the deadline it was solicited, whether they could choose the topic or instead needed to learn about a new subject, and how technical the analysis would be; as Derrick explained, "if it's more technical, with tables and graphs and lots of data, I charge more." Perhaps related to their moral framework emphasizing intrinsic motivation described above, two Knowledge Producers also said they would still complete the job even when they sensed that potential customers could not afford their standard price; as Kizito put it: "Because [I] believe that's [my] calling... So I can't say, give me 200 if you don't have, go. Actually, I rarely send away students even if they don't have it."

Since Knowledge Producers defined good work according to the quality of the output, studentclient interactions were minimized. When delivering the reports to student-clients, most Knowledge Producers provided only a brief overview of what they did. Ronald, for instance, did not feel responsible for teaching student-clients: "My part is getting you the good quality work; your part is understanding what is in that work." John even described feeling accomplished when a lecturer expressed suspicion over whether the student-client did her own research, because this meant they were extremely impressed by the report: "I was also happy and surprised to find that I can do some 
work and someone, a lecturer, says this is done by an expert... I said sorry [to the client], but inside me I was like, how can I make something good like this!'” Others, like Gerald, expressed annoyance when student-clients asked too many questions and took away precious time that could otherwise be spent producing quality research. Derrick said he was willing to work with more inquisitive studentclients if they paid extra, but otherwise he preferred those who asked fewer questions.

\section{Entrepreneurs}

\section{Professional Identity and Moral Distinctions: It's Just a Business}

Entrepreneurs adopted a morally neutral tone when justifying their participation in the research market. Rather than claiming to produce something with intrinsic societal value, they embraced an identity of a businessman who aimed to make money and satisfy customers. Emmanuel acknowledged that lecturers wanted students to complete their own work, but claimed the research market was "unstoppable." As such, he was merely taking advantage of a "window of opportunity" to generate profits: "For us we are looking for something to survive... The business is there." In other words, the system was inevitably broken, so he might as well make a living.

We can see a similar business-oriented professional identity when Wamala was asked how he felt about doing work that others got credit for: "Of course I feel good when I get paid and when the clients tell me they are satisfied, because it shows I have delivered a good service to them." When asked a similar question, Ivan also claimed to have no qualms with it: "You see that there are many shops here. It's a good business." Fred described how he moved over time from viewing student research as a moral breach that violated ethical norms towards viewing it as a morally neutral "product" that falls outside of the ethical domain of research:

I can say that my feelings about this have changed, become somehow softer over time. At the beginning of course to be honest we were guided by values, we did not do [it] because under normal circumstances students are supposed to do research for themselves... So when we started the company, we thought we should not do this because it is in fact unethical. [...] But then after I was doing this work, I came to learn that we shouldn't think of the work as research. This work, what we do for students is not research, because in research you are supposed to find new information. But we never take that route of finding new information. Instead, what we do is we create a product for the client for them to graduate. The information is not real, it is not research as you think of research... If I was maybe doing research for a company that needed to know about this and that, well I would think about it within the ethical values of research. But this is just a product.

As this quote illustrates, by maintaining a boundary between "research," imbued with a moral commitment to discovering new knowledge, and "products," or commodities oriented toward students satisfying a useless requirement, Entrepreneurs posited the market as amoral and justified their behavior as merely market exchange.

The moral boundary between "honest" researchers and those who plagiarized or fabricated data, which was so strong for Knowledge Producers, was not salient for Entrepreneurs. Wamala described how he would falsify data for a hypothetical project: "when you design a tool targeting smokers and non-smokers so you just simply do assumptions. Maybe we talk to 30 people who are 
smokers, you could say about 18 are male 12 female. Why? Because males are more likely to respond as compared to females, so they would a little bit have meaning but you would just fill them in." For Wamala, the ability to avoid going to the field through forging data was one reason why he preferred student research: "You see, nobody will come up to challenge you, they will know what you did really. And you will see that the client, supervisor, everyone is contented." Like Fred above, Wamala articulated how his understanding of these moral boundaries changed over time. When he first began doing student research, he went into the field, but stopped when he realized that "I was doing all that work and nobody really wants it."

\section{Defining the Moral Problem: Meaningless Student Research and Corrupt Universities}

To Entrepreneurs, the fundamental problem underlying the undergraduate research market was that nobody cared about research - neither lecturers, nor students. As Rogers and Kato described, since lecturers disregarded research, so too did students. According to Kato, lecturers often had their own research done by others, creating a hopelessly corrupt system: "The lecturers... just want to see the tables are there, chapter 1 is there, the analysis is there. Most of them didn't do their own research. ... And the students ... come to us, because they see it as something to clear so they can graduate.

They don't care." Rogers similarly disparaged the indifferent lecturers and unmotivated students, and finally exclaimed: "I know I'm doing something that doesn't matter."

Although Entrepreneurs saw no value in student research, they did not consider it inconsequential. On the contrary, Emerson explained that the fact that this requirement could lead many students (especially those lacking means to hire researchers) to "fail to graduate," combined with the fact that "there is no motivation anywhere," resulted in the proliferation of what he called "imagination research" (fake data). Rogers thus concluded: "Yes I'm helping students graduate, they can leave this place and maybe get a job. But it's only [helping] in a small way."

Rather than pointing to students or faculty, Entrepreneurs blamed the pervasiveness of the student research market on the whole university system. They described universities' moral fabrics as irreparably torn, with the research requirement so devalued that it was meaningless. For Fred, the only remedy was for universities to "abandon the whole business" of student research. As Fred explained, students' learning was diminished when they hired researchers, and the work itself was "not honest" because the payments were insufficient for original data collection: "if you do this desk research it can never be an honest research because you have not gone to the field to find out exactly the figures and numbers in reference to the situation." Wamala similarly stated that "research is meaningless" because the system was "broken from both sides" (student and lecturer). When asked whether the situation could be improved, he said simply, "No."

As Wamala's reference to the broken system indicates, Entrepreneurs deemed faculty supervisors complicit in the corruption surrounding undergraduate research. Almost half of the Entrepreneurs described lecturers personally connecting them with particular students whose research projects they were supervising. As Kato said:

There are some lecturers who, when the students bring the proposals, then they call me, they're like 'I have here some work for you. Come'. You go there, this student pays the lecturer 70 thousand, he gives you 30 thousand ... The student will go and do [the 
introduction and literature review], me I'll do [the data analysis and results], then they bind it together.

When assessing students' role in this system, Entrepreneurs, like Knowledge Producers, described their customers as unmotivated. However, unlike Knowledge Producers, rather than characterizing student-clients as generally lazy, Entrepreneurs related students' lack of motivation specifically to their research assignments. As Wamala expressed: "I know when your passion is into a certain direction, I think chances are that you are most likely to excel in that very direction. Now those we do the work [for] do not have their passion in research."

\section{Norms of Professional Conduct: Satisfying Clients and Expanding their Businesses}

Consistent with their business-oriented identities, Entrepreneurs defined good work as satisfying student-clients' specific needs, which also meant considering supervisors' expectations. Rogers emphasized the need to tailor his products: "You cater to all kinds of customers. It's important to learn the needs of each customer, what they want from you, like what kind of work is needed in that course." Austin tried to satisfy supervisors so they would not make trouble for customers: "It's hard to know what each lecturer wants. You find you can do something right and he crosses [it out]... And that creates chaos for the student, they will complain. Each lecturer wants his or her approach."

Entrepreneurs expressed pride in deriving profit from their expanding businesses rather than in producing quality research reports. As Emerson described: "I feel good when I get paid and when the clients tell me they are satisfied, because it shows I have delivered a good service to them. "In direct contrast to Knowledge Producers, who try to conceal their work from loved ones, Emerson openly discussed his business with family and friends, claiming: "I am proud of my business." Similarly, Fred expressed pride that he could send money home: "At least now I can do something... I can save some money at the end of the year. I can support my parents. I started small, this place is now big. I have four computers."

When Entrepreneurs identified challenges related to their work, they pertained to its seasonality and not its illicit nature. Because most universities assigned research projects during the same few months, busy periods were followed by dry spells with few student-clients, especially during the three-month-long holidays. Emmanuel disclosed that this business cycle had even forced him take on debt - exemplifying that although Entrepreneurs boasted the largest shops with the nicest storefronts, they were not free from economic insecurity. Emmanuel continued, however, by saying that besides this lack of consistency throughout the year, he noticed few downsides of doing student research.

\section{Products and Services: Tailor-Made but Falsified Reports}

In contrast to the Knowledge Producers' claims to produce credible work with little regard to their student-clients' experience, Entrepreneurs' work habits were oriented to satisfy students, at the expense of the quality of the reports. For example, to minimize their likelihood of raising the suspicions of the supervisors, Entrepreneurs made their work more or less polished to match the (perceived) abilities of their customers. Emmanuel described inserting errors into the first draft so that supervisors had obvious issues to correct. If a student-client seemed " $d u l l$," Emmanuel planted extra mistakes, to make it look like that student had done the work himself: 
To do good work is to ensure that the student passes with no trouble. You don't want suspicions. So the first time we, even though I know the supervisor's way of doing things, the first time you are giving them work, you don't make it perfect. You put some corrections intentionally. Especially if the student is somehow a little dull. You don't want to give them a perfect product because he [the supervisor] will suspect.

This passage demonstrates how Entrepreneurs' belief that the field of undergraduate research was merely a business opportunity translated into a customer-satisfaction-oriented perspective towards their job. Rather than striving to produce valid information about the social world like Knowledge Producers, Entrepreneurs intentionally added mistakes. And rather than helping students learn like Educators, their goals were, as Emmanuel stated, to make sure that the supervisor believed "it is the student doing the work," to "keep the good relationship" between the supervisor and the studentclient, and to ensure that the customer "is contented."

This satisfaction-oriented perspective runs deeper in shaping their behavior. Because Entrepreneurs had no moral qualms about falsifying data or plagiarizing past work, their knowledge about specific supervisors often determined how real (or fake) the work was. Ivan, for instance, said that his awareness of how strict supervisors were in specific courses determined whether he went to the field or forged the data. Whereas in fields like development studies, the supervisors "aren't so strict, they don't follow much [so] you can just make something up for those ones, " in fields like human nutrition, ethics, or civil engineering, the supervisors "quarrel a lot. Those ones will want you to go to the field." Additionally, Entrepreneurs decided whether to copy from online sources based on the supervisors' likelihood of using plagiarism detection software. As Fred described, "the first thing we ask is whether they will need to give the supervisor a soft or hard copy," because "some lecturers these days demand for soft copies [so] that lecturer can place it in Google or this Turnitin thing." If a lecturer requested a soft copy, Fred explained, "you have to make sure that you do a lot of manipulation so that... it does not present a substantial percentage of plagiarisms. This takes extra time."

On average, Entrepreneurs charged higher prices than researchers in the other two groups (see Table 1). When discussing their pricing, entrepreneurs again adopted business terminology. Using phrases like "price discrimination" (Rogers) and "bargaining power" (Kato), several Entrepreneurs described trying to ascertain a potential client's social class position, observing their clothes and phones and asking them about where they lived. Ivan reported that his prices varied depending on whether he could likely get away with forging or copying. Finally, some Entrepreneurs described upgrading their pricing after making workplace improvements; as Emmanuel said: "In having this office that is looking better, at least now the bargaining power has also risen when you are asking for a higher amount someone can see that you deserve it."

In contrast to Knowledge Producers, who avoided inquisitive student-clients who asked too many questions, Entrepreneurs avoided those with strict supervisors who required too many corrections. Entrepreneurs' central position in the research market around Banda provided them with insider knowledge about specific supervisors and how demanding they were. Rogers described how his years of experience left him knowing which faculty at Technical are "tough about the research 
and make you do a lot of corrections," and he would avoid working with student-clients who were assigned to them. Strict supervisors could force researchers to complete multiple rounds of revision before the assignment was accepted, until it was "not even worth it because the pay [is] too little" (Ivan). Through requesting too many corrections, tough supervisors could also diminish studentclients' satisfaction with the researchers' services. Here, again, Entrepreneurs echoed a pragmatic, business-like moral orientation: Rather than striving to produce a superior piece of work or to teach the student-client useful skills, they aimed to create a satisfactory customer experience.

\section{Educators}

\section{Professional Identity and Moral Distinctions: Helping students learn}

Educators justified their own participation in the research market by emphasizing their efforts to create learning opportunities for others. They drew a moral boundary between researchers like themselves, who devoted time to training students, and other shops, who simply delivered the final product. They articulated a service-oriented, pedagogical professional identity, working to enable students to gain skills they could not learn elsewhere:

Tonny: I always sit down with them, from the start to the end, not like those other places where they just call and say pick up the chapters, they are done. [...] Because they don't get the practical skills for doing research at campus from their classes, they learn it through this work, hearing about what I've done.

This didactic imperative meant that not signing the research projects with their own name (and getting credit for the product) was not an issue. Godfrey claimed to be "proud to do this work" and explicitly invoked an identity of an "educator": "I am an educator... I look at myself as someone who is giving service [to] someone who doesn't know, who can't get that knowledge through usual channels. I feel it is an advantage for them to work with me because they will learn research." Mugisa also described how he tried to involve the student in the process: doing work alongside the student, explaining the work in-depth, preparing the student to present it before the supervisor, and broadly giving the student "ownership of the work" and "making them feel included." For Mugisa, the ideal research process was a collaborative endeavor: "I call it 'our' research so they feel they are included in the process."

\section{Defining the Moral Problem: Lecturers' Failure to Teach and Support Students}

For Educators, the fundamental moral problem underpinning the student research economy was that universities required students to apply skills that they had not been taught. Tonny claimed that Ugandan universities focused on "people excelling in marks" rather than on building transferable skills. He believed students wanted to do research themselves, but lacked requisite knowledge: "We know they would want to do it but they don't know how." Marvin similarly claimed that the problem was not the students, but the institutions, which taught "theory" over "skills" and failed to convey the very basics of research:

A person comes with a topic and you ask very simple questions, like what is the dependent variable? Of course, you have to know the variables before you can 
even start on what you're going to research on. But you find the student knows nothing, they don't even know what that word means, variable. So you find that the way they teach, it's lacking. Research [instruction] in Ugandan universities is so, so lacking.

Educators blamed faculty for failing to teach students these fundamental skills. Mugisa pointed out various problems with faculty, including poor teaching, insufficient class time devoted to research, and limited interactions with students. Ultimately, Mugisa believed that these deficits enticed students to cheat: "You are just meeting a lecturer for the first time when you're doing research. And you know very well that what you are meeting him for you have not mastered it. So in order to avoid that embarrassment, you have to first seek help outside so that you go when you at least have some work." Educators, however, portrayed faculty not as malicious, but rather as overburdened and undertrained. Steven, for example, asserted that faculty were obviously aware that many students outsourced their projects, but understood that students did so because they were not adequately taught in the classrooms. Steven added: "I think they also know that we have means of engaging the client that they don't have."

Educators painted a very sympathetic picture of their student-clients, referring to them as "hardworking" (Lawrence) students who "want to learn" (Tonny). To demonstrate that students were motivated but ill-equipped, Educators explained that most of their student-clients first attempted to complete their projects alone, and only approached the researchers once they got stuck or their work was rejected by their supervisor. Marvin said: "You know that this person is just coming out of frustration from not meeting what the lecturer or the tutor required at that time." As such, Educators painted the market itself as moral, providing much-needed instruction to fill these gaps.

\section{Norms of Professional Conduct: Explaining Their Work to Clients}

This moral orientation resulted in a pedagogic understanding of what constituted good work. Otim emphasized the extra time taken to ensure that the student fully understood: "When these students come, you sit with them and talk to them. You ask, have you understood?" According to Marvin, even when working with student-clients who were "green," he still expected them to come away with a full understanding of the research report. Godfrey described his efforts to rebuild students' confidence after they failed to complete the research without help:

I encourage - I give them time. I tell them that they will learn to do it. I sit them down... say I have written this, this is how they do this, I just got it from these journals that they can access here, from these books here. So they can imagine that they can do research, it is not something so hard.

This orientation toward helping students learn was a source of pride for the Educators. As Lawrence put it: "For me it does not make me feel good doing work for marks, if I spend my brains on something that is only a mark on someone else's transcript." What made the experience "better" was when he worked with those "who really want to learn." In those cases, "There is a purpose, I am helping them get somewhere." Tonny expressed feeling a similar sense of purpose when working with older students: "There is more respect there... That guy has a family, he is working, he knows 
what you are doing and when he comes here he has come for assistance not to buy words. He has come for someone to teach him, to help him go ahead on his own."

Conversely, Educators bemoaned situations when student-clients failed to defend their work to their supervisors. Unlike Knowledge Producers, who viewed this situation as a failure by the student, Educators often blamed themselves. As Steven said: "When you do work with someone and he cannot explain what is there to the supervisor, then that means you have not done anything. If the supervisor suspects that the client has not done the work himself, that one is my fault."

Educators also expressed broader dissatisfaction that despite their best efforts, many students never gained a thorough understanding of research. Marvin said: "it's like you are graduating minus knowing what you are supposed to have done... It is also a disadvantage to those guys that don't feel they can really do their own research." This was, again, in contrast to Knowledge Producers, who expressed frustration that student-clients benefitted too much (through good grades and jobs) from the research they procured.

\section{Products and Services: Straightforward Reports, Extended Student Interaction}

Unlike Knowledge Producers, who worked to create sophisticated projects, Educators worked to make their work readily comprehensible by their student-clients. For example, Godfrey described how he avoided "complicated words" in his writing so that it could be read and understood easily. And whereas Entrepreneurs worked so that the final product deflected the lecturers' suspicion, Educators worked to ensure that the student-client could effectively defend the report they had purchased. Most Educators, like Lawrence, depicted an extended back and forth process with student-clients:

When I am doing your work I have to first tell you in detail what I have done and what the findings are... Then, you have to present it back to me, what you have heard me say. I tell you what you got wrong, then explain again what I have done. Then you the student go home and read it in full and try to understand it, and then we meet again and talk about anything you [didn't] understand. So that when meeting with the supervisor, any question, you are able to answer it.

On average, Educators charged the lowest price among the three groups of researchers (see Table 1). When asked about their pricing practices, Educators had less to say than the other two groups, suggesting that they did not vary their prices as much between customers (perhaps because they were less likely to attract more advantaged students due to their locations and smaller reputations). Marvin explained that, "the prices are different according to courses," with engineering attracting the highest price, but confessed that "I have never done one of those." Mugisa explained that his prices had slowly increased as he gained more experience; at first he provided research free of charge for friends, then charged less than half of his current rate before eventually raising the price again.

In contrast to Knowledge Producers, who avoided time-consuming student-client interactions, Educators complained about students who refused to spend time learning what they had done and simply demanded the final product. As Tonny said: "Of course, not all students want to learn. There are those they just want to bring to you the topic, pay the money and leave. [...] We refuse those 
students who won't take the time to learn what we've done." Lawrence also said he "personally avoid [s]" students who "drop off the topic" and prefers those who "take the time to sit and learn, make corrections" Godfrey, too, complained about student-clients who "come during the time for deadlines when the time is too short for them to manage that kind of research" and then "refuse to meet with us to discuss the work, they say just send it to me." In these cases, he would withhold work that he had promised: even if they had already paid him, he refused to complete the rest of the report unless they met with him. Godfrey justified this practice as a way to "motivate" students to invest time and "try to understand."

\section{DisCUSSION AND CONCLUSIONS}

The two campuses in this study exemplify contrasting "economies of worth" (Boltanski and Thevenot 2006) - the dominant culture surrounding the preeminent Flagship University values academic excellence and the pursuit of new knowledge, whereas the dominant culture surrounding the middle-ranking Technical University, values entrepreneurship, financial success, and social connectedness. When we first extended our study of the student research market from Technical into Flagship, we expected to find that these different institutional environments would foster different professional identities and moral frameworks through which researchers made sense of their trade. Indeed, Knowledge Producers, who studied and worked around Flagship, prized intellectual purity and extoled research's inherent societal benefits, similar to the academically-oriented scientists in Shapin's study (2008). Researchers in this group considered research itself sacred and thus experienced shame due to the illicit and commodified nature of the student research market. Nevertheless, they distinguished themselves from those they believed to be bastardizing the purity of research and retained some hope that their work could still contribute to a better understanding of the world, even as others accepted credit for it.

Entrepreneurs, on the other hand, constructed a professional identity and moral framework that echoed the dominant institutional culture of Technical, where most of them had been successful students. Entrepreneurs espoused a professional identity resembling that of Shapin's (2008) entrepreneurial scientists, which extoled the profitability and monetization opportunities available in the research market. However, since they viewed student research as meaningless and thus removed from the moral sphere, they expressed no moral qualms about selling student work, and instead felt pride as successful business owners who could satisfy each customer.

Had we found only these two groups, our findings would have been consistent with those of Reich (2014), who shows that market participants' moral frameworks are rooted in the institutional contexts in which they are embedded. However, we also identified a third group of researchers, Educators, who were evenly split across the two university campuses, but whose moral frameworks nonetheless cohered around a stable set of values. Akin to Lareau's (2015) cultural guides, Educators derived meaning from their work by helping others decode institutional rules of the game and prized this ability above intellectual fulfillment or pecuniary interests. Our data strongly suggest that it was not institutional positioning alone, but Educators' experiences of inferior class positioning within their academic institutions that led them to construct a professional identity oriented towards equipping others with tools to navigate and succeed in alienating and unequal campus cultures. 
This third group underscores the notion that morals are not uniform across markets or within institutions; instead, they depend on an individual's location in a given institutional context and map onto local structures of inequality. Researchers' professional identities and moral frameworks, which they draw upon when justifying their participation in the illicit market, reflect their differential access to the locally dominant regimes of valuation and are produced in relation to their classed experiences. These frameworks result in researchers' distinct attitudes and practices related to research and market activity, placing some of them in a better position to attain an ascendant position in the market, while further marginalizing others. Rather than converging into one dominant, "legitimating" (Livne 2014) framework over time, these frameworks and identities may lead to further diversification of this crowded marketplace.

Like all interview studies, we are somewhat limited in our ability to assess whether these moral perspectives are expressed in order to appear virtuous during the interview, or whether they instead run deeper in shaping participants' thoughts and behavior. Our ethnographic evidence, however, strongly suggests that researchers' moral frameworks do run deeper. During observations in the research shops, the three groups of researchers engaged in objectively different systems of organization and habits of work, which were consistent with their stated moral commitments and descriptions of their market practices. The moral frameworks were also remarkably consistent among individuals within each group (and quite different across the groups). They both mapped onto researchers' narratives about their previous experiences and corresponded to their current market positions.

The theoretical model that we introduce in this paper should not be interpreted as an exhaustive account of the causal processes at play, in our case or in other potential applications of this model. In the student research market, there may be other factors influencing researchers' moral sensemaking that were not captured in the interviews and observations, and researchers' social class positionings likely influence their products and services through other mechanisms besides the one that we elucidate here. Nor is a study of a single market, at one point in time, appropriate for making broadly generalizable claims. Instead, our goal is to advance theoretical insights that are situationally conditional, while also elucidating potential causal mechanisms that may be applicable to actors in different markets.

Particularities of our case may also limit the potential for our theoretical model to apply to other markets and institutional settings. Compared to most other institutions, universities are unique in the extent to which they are hierarchically arranged according to prestige and social status. We are unable to ascertain whether our results will be relevant to other fields in which different institutions are not hierarchically differentiated by status, but still espouse different cultural systems of valuation. Nonetheless, we contend that while the rankings may be less explicit, many institutions of interest to scholars of moralized markets are similarly positioned unequally vis-à-vis one another. For example, hospitals and hospices are often informally stratified due to their differing reputations and access to resources, even if these classifications do not amount to formal rankings. Restaurants, too, are hierarchically arranged into tiers - e.g., fine dining versus family friendly — and these status differences affect the culture of these institutions and the behavior of the workers who populate them. As described above, even illicit marketplaces such as the illegal drug trade are often characterized by internal hierarchical arrangements. Scholars of moralized markets must therefore account for the 
effects of the unequal positioning of the institutions they study, in addition to their cultural heterogeneity, when examining workers' differing moral orientations to their trades.

Despite these limitations and particularities, we hope that this model will be helpful for other researchers studying morally contested markets. For example, Zelizer (2005) reveals how the social dynamics of monetary exchanges allow men to symbolically differentiate between marital relations and prostitute-client encounters. But illicit sexual encounters are also influenced by the identity work and moral boundaries enacted by the women themselves, which vary across the occupational hierarchies of indoor versus outdoor, street versus escort (Bernstein 2007; Murphy and Venkatesh 2006). What might we learn if we combined these insights? Closer to home, sociologists continuously grapple with the question of what kind of research we should pursue, and groups of scholars articulate divergent moral orientations to our field. Some articulate a "mission-oriented" moral orientation that foregrounds public engagement and social justice, whereas others articulate a "knowledge-oriented" moral orientation that foregrounds disciplinary debates and empirical precision (Dromi and Stabler 2019; Romero 2020). To what degree might the differing professional identities and moral orientations that we bring to our work map onto social and institutional inequalities within academia? Exploring this empirical question may help us to better understand how our field, like all fields, is differentiated by producers of knowledge.

We identify two primary implications of this article for scholarship on moralized markets. First, building on the work of Anteby (2010), we demonstrated that the moral distinctions actors draw around their work contribute to the creation of differentiated spheres in the market. We have further extended this work by showing that researchers' moral distinctions are rooted in their classstratified and institutionally-delineated positions in the market, and as such, market spheres map onto local structures of inequality. Second, we have shown that these producer-differentiated moral frameworks - as well as the identity work and moral sensemaking that market actors engage in translate into distinct practices of production. Whereas Knowledge Producers strove to generate research contributing to our scientific understanding of the world, Entrepreneurs purposefully planted mistakes in the students' reports, and Educators focused on generating work that would be accessible to the students and enhance their university experiences. Although we were unable to access and evaluate the actual written reports, researchers' different orientations within this "moral economy of science" (Daston 1995) suggest we ought to pay more attention to how moral values influence the production processes of contested commodities.

This research also has implications for scholars interested in emergent markets in the knowledge economy. As the global field of higher education becomes increasingly competitive, and university degrees serve as signifiers of individual status and worth, products and services designed to help students attain these markers become laced with moral meanings. In Taiwan, for example, college admissions services are defined as moral when they compensate for applicants' disadvantages (e.g., editing essays written by non-native English speakers) but as immoral when they help advantaged students further cement their privileged access to competitive schools (Chen and Berman 2020). And as the 2019 college admissions scandal laid bare, in the United States, some advantaged families approach the college application process with a distinct moral framework, aimed at avoiding downward mobility at all costs. Academic excellence, like research production, is laden 
with moral weight; how people carry that weight is a product of how they strive to position themselves in an unequal system. 


\section{REFERENCES:}

Abbott, Andrew. 1988. The System of Professions: An Essay on the Division of Expert Labor. University of Chicago Press.

Adler, Patricia A. 1993. Wheeling and Dealing: An Ethnography of an Upper-Level Drug Dealing and Smuggling Community. Columbia University Press.

Altomonte, Guillermina. 2020. "Exploiting Ambiguity: A Moral Polysemy Approach to Variation in Economic Practices." American Sociological Review 85(1): 76-105.

Anteby, Michel. 2010. "Markets, Morals, and Practices of Trade: Jurisdictional Disputes in the US Commerce in Cadavers." Administrative Science Quarterly 55 (4): 606-638.

Armstrong, Elizabeth A., and Laura T. Hamilton. 2013. Paying for the Party: How College Maintains Inequality. Harvard University Press.

Bandelij, Nina. 2020. "Relational Work in the Economy" Annual Review of Sociology 46:251-272.

Bernstein, Elizabeth. 2007. Temporarily Yours: Intimacy, Authenticity, and the Commerce of Sex. University of Chicago Press.

Binder, Amy and Andrea Abel. 2018. "Symbolically Maintained Inequality: How Harvard and Stanford Students Construct Boundaries Among Elite Universities." Sociology of Education 92(1): 41-58.

Boltanski, Luc, and Laurent Thévenot. 2006. On Justification: Economies of Worth. Princeton University Press.

Bourdieu, Pierre. 1996 [1989]. The State Nobility: Elite Schools in the Field of Power. Stanford University Press.

Carruthers, Bruce and Wendy Espeland. 1998. "Money, Meaning, and Morality." American Behavioral Scientist 41(10): 1384-1408.

Chen, Kenneth H. and Berman, Elizabeth P. 2020. "Buying into the Meritocracy: Taiwanese Students and the Market for College Admissions Services." Presented at the American Sociological Association Annual Meeting.

Daston, Lorraine. 1995. "The moral economy of science." Osiris 10: 2-24.

Decoo, Wilfried. 2001. Crisis on Campus: Confronting Academic Misconduct. MIT Press.

Dioun, Cyrus. 2018. "Negotiating moral boundaries: Social movements and the strategic (re)definition of the medical in cannabis markets." Research in the Sociology of Organizations 56: 53-82.

Dodd, Nigel. 2005. "Reinventing Monies in Europe." Economy and Society 34(4): 558-583. 
Dromi, Shai and Samuel Stabler. 2019. "Good on Paper: Sociological Critique, Pragmatism, and Secularization Theory." Theory and Society, 48(2): 25-350.

Fourcade, Marion. 2011. "Cents and Sensibility: Economic Valuation and the Nature of "Nature"." American Journal of Sociology 116(6): 1721-77.

Fourcade, Marion. 2012. “The Moral Economy of Viviana Zelizer.” Sociological Forum 27(4): 1055-1061.

Fourcade, Marion, and Kieran Healy. 2007. "Moral Views of Market Society." Annual Review of Sociology 33(1): 285-311.

Healy, Kieran. 2006. Last Best Gifts: Altruism and the Market for Human Blood and Organs. University of Chicago Press.

Jack, Anthony. 2019. The Privileged Poor: How Elite College are Failing Disadvantaged Students. Harvard University Press.

Kaija, Wilson Akiiki. 2017. "Uganda: Mercenaries Killing the Quality of Graduates” The Monitor. May 15.

Karabel, Jerome. 2006. The Chosen: The Hidden History of Admission and Exclusion at Harvard, Yale, and Princeton. Houghton Mifflin Harcourt.

Karandinos, George, Laurie Hart, Fernando Castrillo, and Philippe Bourgois. 2014. "The Moral Economy of Violence in the US Inner City." Current Anthropology 55(1):1-22.

Lareau, Annette. 2015. "Cultural Knowledge and Social Inequality.” American Sociological Review 80(1): 1-27.

Larson, Magali Sarfatti. 1979. The Rise of Professionalism: A Sociological Analysis. University of California Press.

Lee, Elizabeth. 2016. Class and Campus Life: Managing and Experiencing Inequality at an Elite College. Cornell University Press.

Livne, Roi. 2014. "Economies of Dying: The Moralization of Economic Scarcity in US Hospice Care." American Sociological Review 79(5): 888-911.

Lucier, Paul. 2009. "The Professional and the Scientist in Nineteenth-Century America." Isis 100(4): 699-732

Murphy, Alexandra and Sudhir Venkatesh. 2006. "Vice Careers: The Changing Contours of Sex Work in New York City." Qualitative Sociology 29(2): 129-154.

Newton, Philip. 2018. "How Common is Commercial Contract Cheating in Higher Education and Is It Increasing? A Systematic Review.” Frontiers in Education 3:67. 
Quinn, Sarah. 2008. "The Transformation of Morals in Markets: Death, Benefits, and the Exchange of Life Insurance Policies.” American Journal of Sociology 114(3): 738-780.

Reich, Adam D. 2014. "Contradictions in the Commodification of Hospital Care." American Journal of Sociology 119(6): 1576-1628.

Rivera, Lauren. 2016. Pedigree: How Elite Students Get Elite Jobs. Princeton University Press.

Romero, Mary. 2020. "Sociology Engaged in Social Justice” American Sociological Review 85 (1), $1-30$.

Snow and Anderson. 1987. "Identity Work Among the Homeless: The Verbal Construction and Avowal of Personal Identities" American Journal of Sociology 92(6): 1336-1371.

Shapin, Steven. 1994. A Social History of Truth: Civility and Science in Seventeenth-Century England. Chicago University Press.

—. 2008. The Scientific Life: A Moral History of a late Modern Vocation. University of Chicago Press.

Shavit, Yossi, Richard Arum, and Adam Gamoran (eds). 2007. Stratification in Higher Education: A Comparative Study. Stanford University Press.

Smith, Tovia. 2019. "Buying College Essays Is Now Easier Than Ever. But Buyer Beware” National Public Radio. April 19.

Stockman, Farah, and Carlos Mureithi. 2019. "Cheating, Inc.: How Writing Papers for American College Students Has Become a Lucrative Profession Overseas." The New York Times, September 7.

Wherry, Frederick. 2012. The Culture of Markets. Polity.

Zelizer, Viviana. 1983. Morals and Markets: The Development of Life Insurance in the United States. Transaction Books.

—. 1997. The Social Meaning of Money. Princeton University Press.

—. 2005. The Purchase of Intimacy. Princeton University Press. 
Figure 1. Two signs advertising research assistance on a tree inside the Flagship University campus.

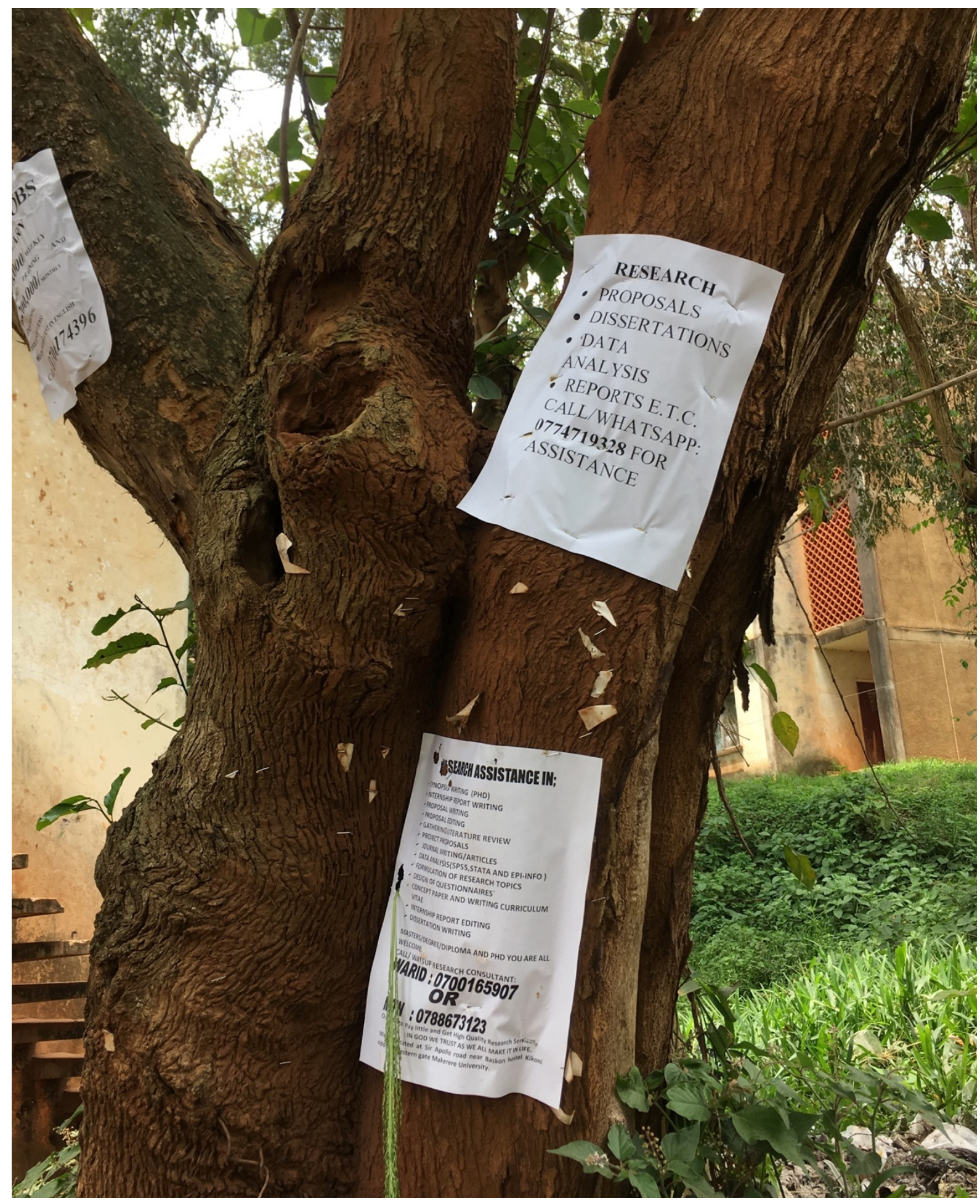


Figure 2 . A centrally-located research shop in Banda with professionally printed signs.

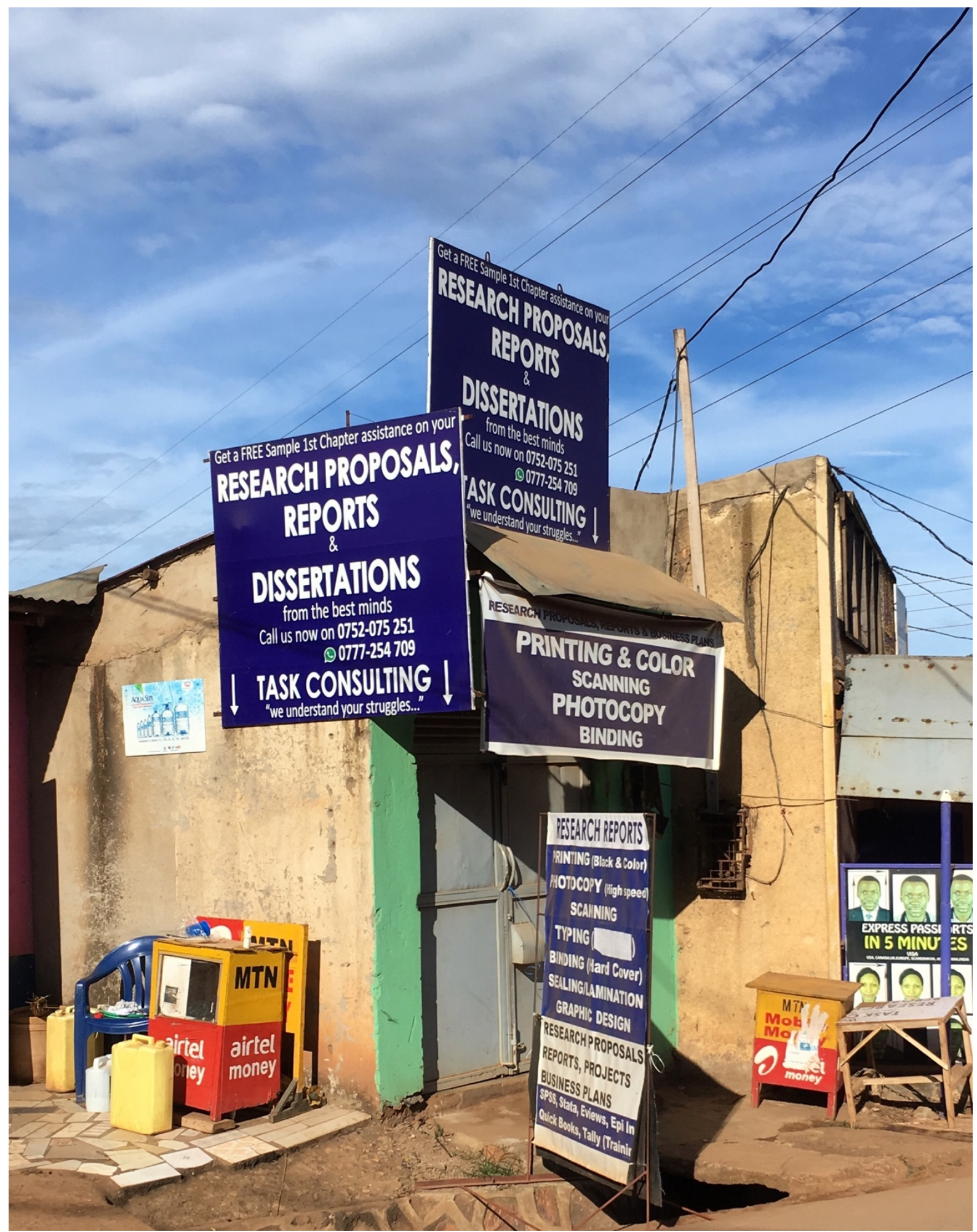


Figure 3. Map of Banda, each blue dot $(\mathrm{N}=84)$ represents a shop advertising research services.

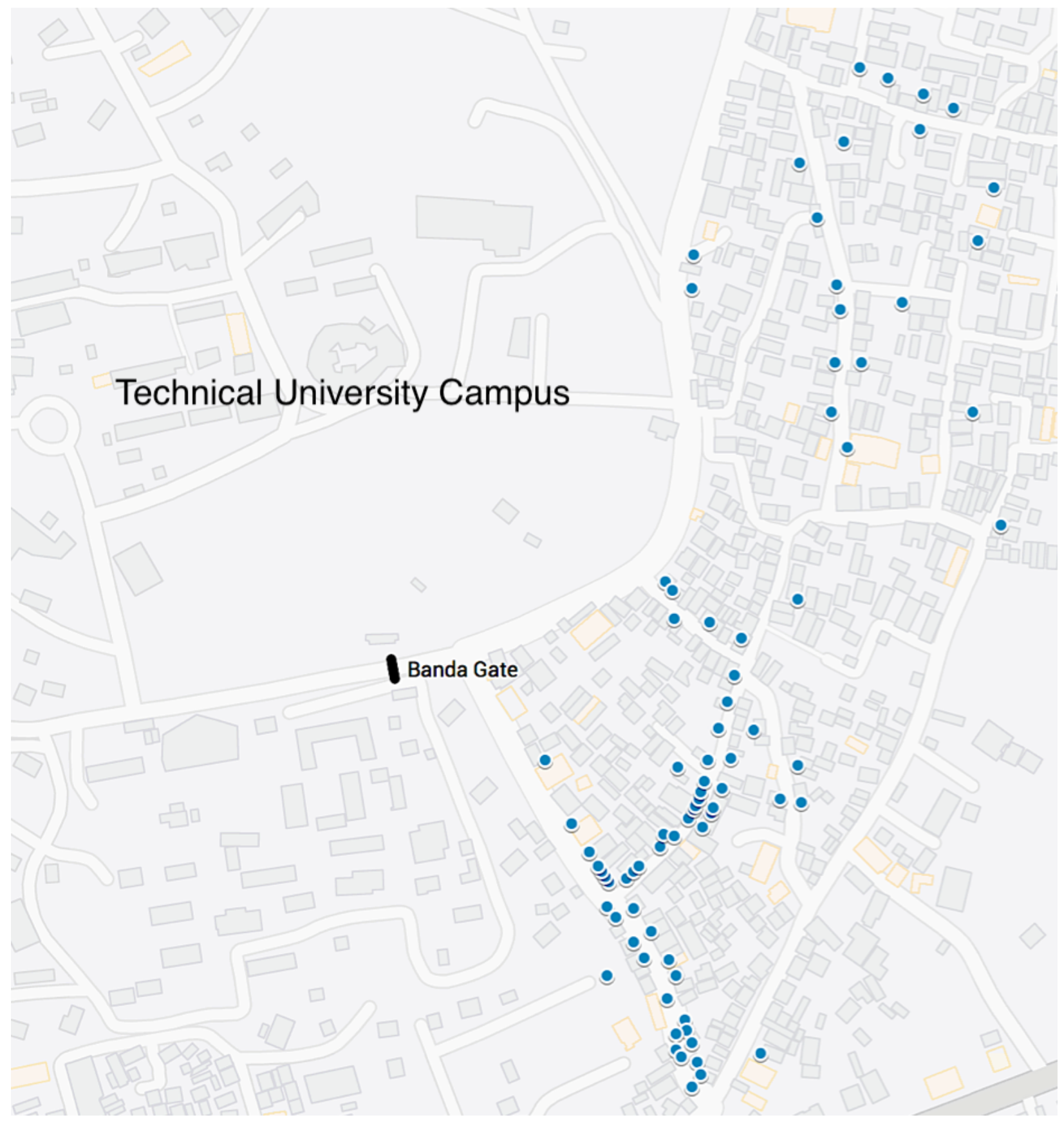

Note: To create this map, the first author and one of the key informants walked slowly down every street in Banda, and used a mapping application on our cell phones to add a pin every time we saw a business that advertised student research outside. In total, we identified 84 shops, and the largest distance between two shops was $1.1 \mathrm{~km}$. 
Figure 4. A smaller, less centrally-located shop in Banda with hand-printed signs.

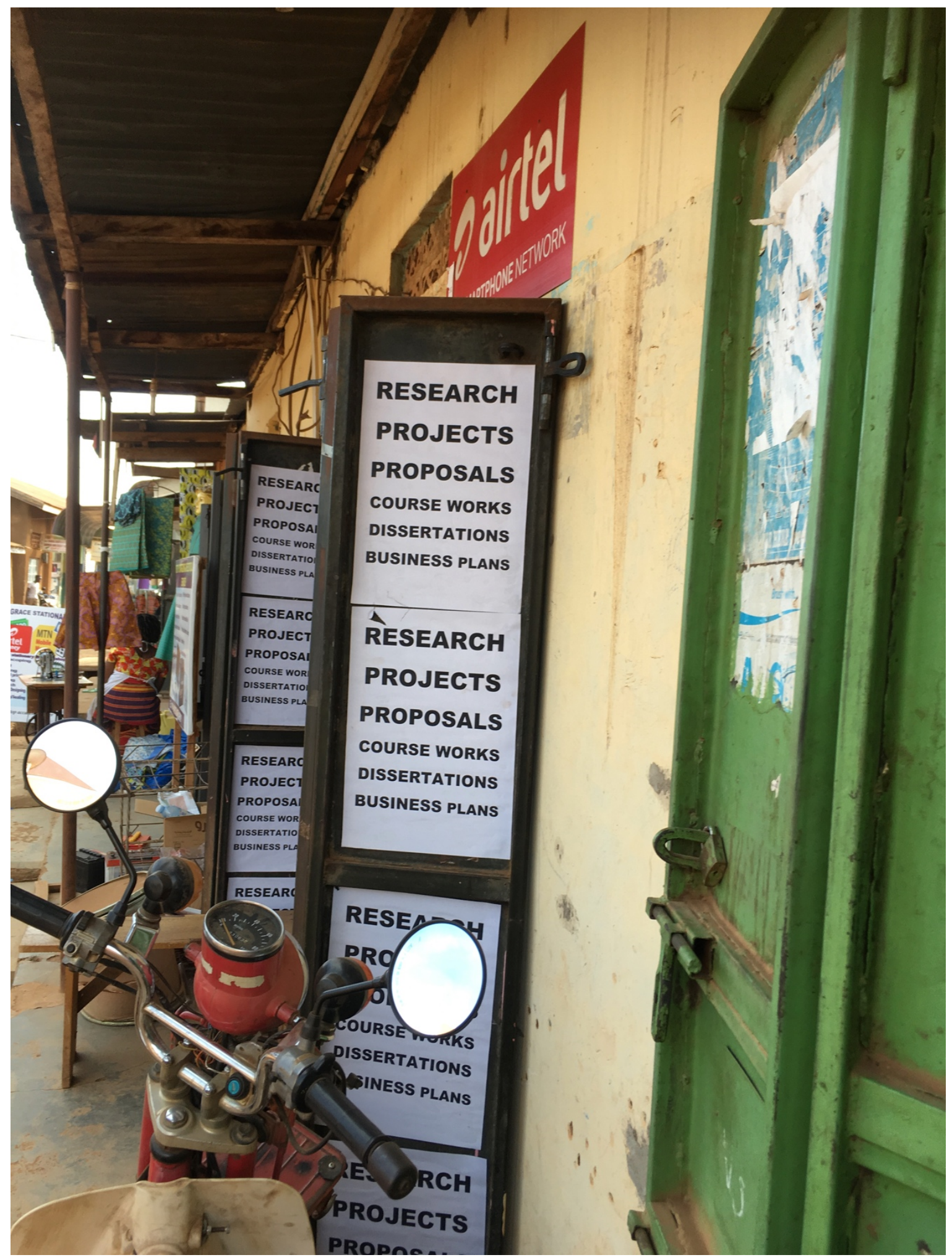


Table 1. Summary of the Findings: Distinctions Between the Three Groups of Researchers

\begin{tabular}{|c|c|c|c|}
\hline Element of comparison & Knowledge Producers & Entrepreneurs & Educators \\
\hline Institutional background & Flagship University & Technical University & Both \\
\hline \multicolumn{4}{|l|}{ Class-stratified trajectories } \\
\hline Family background & Urban, middle-class & Middle- and upper-middle class & Rural, poor \\
\hline College experience & Excellent students & Socially connected business students & Struggling but diligent students \\
\hline Entry into the field & $\begin{array}{l}\text { Inability to secure formal } \\
\text { employment }\end{array}$ & $\begin{array}{l}\text { Choice after quitting other jobs, } \\
\text { reliance on social capital }\end{array}$ & Experience of abject poverty \\
\hline Current market position & $\begin{array}{c}\text { Smaller shops near Flagship, } \\
\text { ambition to exit the field and do 'real } \\
\text { research' }\end{array}$ & $\begin{array}{l}\text { Large shops in Banda, seeking to } \\
\text { expand their businesses and do more } \\
\text { profitable work }\end{array}$ & $\begin{array}{l}\text { Both campuses and smaller shops, } \\
\text { seeking to expand their businesses }\end{array}$ \\
\hline \multicolumn{4}{|l|}{$\begin{array}{l}\text { Professional identities and moral } \\
\text { frameworks }\end{array}$} \\
\hline Moral perspective of the market & $\begin{array}{l}\text { 'Fake' student research compromises } \\
\text { research ideals; Market is immoral }\end{array}$ & $\begin{array}{l}\text { There is no value in student } \\
\text { research; Market is amoral }\end{array}$ & $\begin{array}{l}\text { University fails to teach necessary } \\
\text { skills; Market is moral }\end{array}$ \\
\hline Attribution of blame & Lazy, wealthy students & Corrupt system & Lecturers \\
\hline Moral justification & $\begin{array}{l}\text { Producing 'real' research, pursuing } \\
\text { passion and self-improvement }\end{array}$ & $\begin{array}{l}\text { Delivering the agreed-upon product, } \\
\text { further expanding business }\end{array}$ & $\begin{array}{l}\text { Educating the students about research } \\
\text { and helping them succeed }\end{array}$ \\
\hline \multicolumn{4}{|l|}{$\begin{array}{l}\text { Differentiated products } \\
\text { and services }\end{array}$} \\
\hline Definition of "good work" & $\begin{array}{l}\text { Producing quality reports that may } \\
\text { reach broader audiences }\end{array}$ & $\begin{array}{l}\text { Producing a satisfactory } \\
\text { customer experience }\end{array}$ & $\begin{array}{l}\text { Producing a better-informed and } \\
\text { more confident student-client }\end{array}$ \\
\hline Research reports & Original data, sophisticated methods & Tailor-made but often falsified & $\begin{array}{c}\text { Straightforward language, simpler } \\
\text { methods }\end{array}$ \\
\hline Interactions with student-clients & $\begin{array}{l}\text { Minimal interaction, disregard for } \\
\text { coaching them to meet supervisors }\end{array}$ & $\begin{array}{l}\text { Some interaction, work to ascertain } \\
\text { supervisors' and clients' preferences }\end{array}$ & $\begin{array}{l}\text { Intensive interaction, teach student } \\
\text { about the whole research process }\end{array}$ \\
\hline $\begin{array}{l}\text { Mean Estimated Price for } \\
\text { Undergraduate Research }\end{array}$ & $\begin{array}{l}\text { 280,000 Shillings } \\
\text { (USD 75) }\end{array}$ & $\begin{array}{l}\text { 385,000 Shillings } \\
\text { (USD 103) }\end{array}$ & $\begin{array}{l}\text { 240,000 Shillings } \\
\text { (USD 64) }\end{array}$ \\
\hline
\end{tabular}


Appendix Table A1. Characteristics of Researchers Quoted or Referred to in Text

\begin{tabular}{|c|c|c|c|c|c|c|}
\hline Group & Pseudonym & $\begin{array}{l}\text { Campus } \\
\text { attended }\end{array}$ & Major & $\begin{array}{l}\text { Location of } \\
\text { shop }\end{array}$ & Size of Shop & $\begin{array}{l}\text { Distance from } \\
\text { campus }\end{array}$ \\
\hline \multirow{8}{*}{$\begin{array}{l}\text { Knowledge } \\
\text { Producers }\end{array}$} & Derrick & Flagship & Population Studies & Flagship & small & On campus \\
\hline & John & Flagship & Social Sciences & Flagship & medium & Somewhat far \\
\hline & Ronald & Technical & Information Technology & Banda & small & near (side street) \\
\hline & Kizito & Flagship & Social Sciences & Flagship & small & near (side street) \\
\hline & Gerald & Flagship & Information Technology & Flagship & medium & near (side street) \\
\hline & Joel & Technical & Economics & Banda & medium & near (side street) \\
\hline & Moses & Flagship & Population Studies & Flagship & small & On campus \\
\hline & Jacob & Flagship & Social Sciences & Flagship & medium & Somewhat far \\
\hline \multirow{8}{*}{ Entrepreneurs } & Rogers & Technical & Economics and Statistics & Banda & large & near (main street) \\
\hline & Emerson & Flagship & Business Communication & Banda & large & near (main street) \\
\hline & Kato & Technical & Business Studies & Banda & large & near (main street) \\
\hline & Ivan & Technical & Economics and Statistics & Banda & medium & near (side street) \\
\hline & Emmanuel & Technical & Business Studies & Banda & medium & near (main street) \\
\hline & Wamala & Technical & Finance & Banda & medium & near (side street) \\
\hline & Fred & Technical & Business Communication & Banda & large & near (side street) \\
\hline & Austin & Technical & Economics and Statistics & Banda & large & somewhat far \\
\hline \multirow{7}{*}{ Educators } & Marvin & Technical & Accounting & Banda & medium & somewhat far \\
\hline & Tonny & Flagship & Development Studies & Flagship & small & somewhat far \\
\hline & Mugisa & Flagship & Accounting & none & works from home & none \\
\hline & Godfrey & Flagship & $\begin{array}{c}\text { Records and Archives } \\
\text { Management }\end{array}$ & Flagship & small & far \\
\hline & Lawrence & Technical & Information Technology & none & works from home & none \\
\hline & Steven & Technical & Business communication & Banda & small & far \\
\hline & Otim & Technical & Anthropology & Banda & small & far \\
\hline
\end{tabular}

